Volume (3) No. (2) 2020

التصورات الإبستمولوجية لمعلمي الرياضيات حول المعرفة المفاهيمية في مراحل التعليم العام بمدينة حائل

د. محمد حمد معتق الخزيم 
التصورات الإبستمولوجية لمعلمي الرياضيات حول المعرفة المفاهيمية في مر احل التعليم العام بمدينة حائل د. محمد حمدمعتق الخزيم

أستاذ تعليم الرياضيات المشارك، كلية التربية، جامعة حائل، السعودية

Moyar_3@hotmail.com

قبلت للنشر في 12/12/ 2019م

قدمت للنشر في 2019/10/29م

ملخص: استهدفت الدراسة الحالية الكشف عن التصورات الإبستمولو جية للمعرفة المفاهيمية لدىن عينة من معلمي الرياضيات، وتكونت العينة من (33) معلمًا من معلمي الرياضيات بمر احل التعليم العام بمدينة حائل المملكة العربية السعودية، استخدم الباحث المنهج الوصفي التحليلي والاستبيان كأداة لجمع المعلومات حول التصورات الإبستمولوجية للمعرفة المفاهيمية، وأظهرت الدراسة بعد جمع البيانات وتحليلها أن التصورات الإبستمولو جية لدىن معلمي الرياضيات بمر احل التعليم العام حول طبيعة المفاهيم الرياضية وتعلمها كانت بدرجة عالية، كما أظهرت النتائج وجود فروق دالة إحصائيّا في التصورات الإبستمولوجية تعزىن لمتغيري المرحلة التعليمية والخبرة التدريسية، بينما لا توجد فروق ذات دلالة إحصائية تعزىن لمتغير المؤهل العلمي، وتقدمت الدراسة بعدد من التوصيات أهمها تعزيز التصورات والمعتقدات الإبستمولوجية حول طبيعة المعرفة المفاهيمية لدى' معلمي الرياضيات، تنمية مهاراتهم التدريسية في ضوء تصوراتهم ومعتقداتهم الإبستمولوجية للمعرفة المفاهيمية وأساليب تعلمها وتعليمها.

الكلمات المفتاحية: التصورات الإبستمولوجية، معلم الرياضيات، المعرفة المفاهيمية. 


\section{Epistemological Perceptions among Mathematics Teachers about}

\section{Mathematical Concepts}

Mohammad Hamad Muaitq alkhuzaim

Associate professor of Mathematics Education, College of Education,

University of hail, Saudi Arabia

Moyar_3@hotmail.com

\section{Received in 29th October 2019}

accepted in 1st

\section{December 2019}

Abstract: The current study aims to investigate the epistemological perceptions of conceptual knowledge among a sample of mathematics teachers. The sample was composed of thirty-three (33) teachers of mathematics at different stages of general education in the city of Majmaah, Kingdom of Saudi Arabia. The researcher adopted the descriptive analytical method and questionnaire as tools to collect information about epistemological perceptions of conceptual knowledge. Data collection and analysis showed that epistemological perceptions of the conceptual knowledge of mathematics teachers in general education stages on the nature of mathematical concepts and their learning were high. Furthermore, the results showed statistically significant differences in epistemological perceptions due to the variables of educational level and teaching experience, while no statistically significant differences were found with respect to the educational qualification variable. The study has made a number of recommendations. Most importantly, the Ministry should hold training courses for teachers of mathematics in general education stages with the aim of promoting their epistemological perceptions and beliefs about the nature of the conceptual knowledge.

Keywords: Epistemological Perceptions, Mathematics Teacher, Mathematical Concepts 


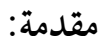

إن إدراك طبيعة علم الرياضيات من قبل معلميها يساهم بشكل كبير في نجاح تعليم الرياضـيات وتعلمها، فتعليم الرياضـيات وتعلمها يعتمد بشـكل أسـاسي على المعلم ومدىن معرفته ومعتقداته وت صور اته نحو علمها وطبيعتها وأ ساليب تعلمها وتعليمها؛ فالتعرف على قدرات المعلم المختلفة ومدى فهمه لطبيعة الرياضـيات تنعكس ايجابيا علن قدرات المتعلمين وتوظيفها بها يعمل على تحقيق أهداف تدريس الرياضيات (أبوجحجوح، 2013). إن فهم معلم الرياضـيات لطبيعتها يتطلب أن يدرك أصــل المعرفة بعلم الرياضـيات وطرق تعليمها وتعلمها؛ فمعرفة المعلم وفهمه لطبيعتها تؤثر في طريقته وأسـاليبه في تقديمها للمتعلم، حيث يرى البر صان وزملاؤه أن تمكن معلم الريا ضيات من تدريد سها يتطلب ذلك الكشف عن طريق تفكيره والافتراضات المعرفية التي ينطلق منها في بناء المعرفة، وهذا يتطلب الـ سير في أعحاق طبيعة المعرفة الريا ضية التي يمتلكها معلم الريا ضيات وكيف تنعكس داخل غرفة الصف (البرصان وزملاؤه، 2017). ويعد علم الريا ضيات من العلوم التي تتميز بطبيعة تميزه عن غيره وله فلسفته الخاصة به، وله الأ صول المعرفية المتعلقة به، فينبغي إدر الك وفهم معلم الريا ضيات لهذه الطبيعة المميزة للرياضـيات و إدر اكه لأصــول المعرفة وفلسـفة علم الرياضـيات، حيث يعد مؤشرًا لامتلاك المعلم تصورات ومعتقدات حول طبيعة المعرفة الرياضية وطرق الو صول إليها، والذي يطلق عليه التصــورات الإبســمولوجية الذي تعرف بنظرية المعرفة والتي تعتبر نظام عقدي لدىن الفرد يتمثل في المهارات المرتبطة بحدود معرفته وبطبيعة المشـكلات التي تواجهه، ويسـعنى للتفريق بين المعرفة الصحيحة والخاطئة (القادري، 2012 ). ويعتبر مصــطلح الإبسـتمولوجية والتي يقصـــ بها نظرية العلم والمعرفة ومصــلح في اللغة الفرذسية مركب من الكلمة اليونانية episteme حيث تعني العلم (Epistemologie) 
أو المعرفة العلمية والمقطع logie الذي يعني في أصل اليونانية (Logos) نظرية أو دراسة نقدية؛ وبناء عليه فإن لفظ إبتســمولوجية يُعنى بحكمى أصـله الاشـتقاقي في نظرية المعرفة العلمية (بلانشيه، 1986) فالإبستمولوجية هي الدراسة النقدية لمبادئ العلوم وفرو ضها ونتائجها بغرض تحديد أ صلها المنطقي وبيان قيمتها وح صيلتها المو ضوعية ويق صد بها أيضًا فل سفة العلوم جميعها، وهي تعني في المقام الأول بيان شروط المعرفة البشرية، وقيمتها، وحدودها، ومو ضوعيتها من زاوية تطور العلم المعاصر، والإبسـتمولوجية ترتبط بنظر ية المعر فة كما ترتبط بالمثيودلوجيا وفلسـفة العلوم والمنطق، فهي تدرس شروط المعر فة الصــحيحة شــأ نها شـــأن المنطق، فالإبستمولوجية فرعُ من فروع فلسفة العلم التي تهتم بطبيعة وبجال المعرفة للتعرف على ماهية المعرفة وكيف يمكن امتلاكها (عفيفي، 2015)، بينها المعتقدات والتصورات الإبستمولو جية

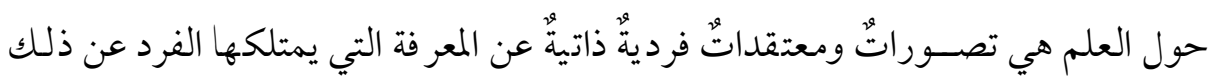

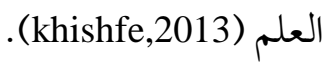

ويرىن سـليمان وزملاؤه أن الإبسـتمولو جية نظام عقائدي لدى الفرد يؤثر في تعلمه . وخبراته، وفي بناءه المعرفي، وتحققه من دقة ابنيته المعرفية لأنها تبحث بحدود المعرفة، وبطبيعة المعرفة ذاتها وطرق الوصــول اليها وبقضـايا المنهجية العلمية ها (القادري والمومني وقبلان،

ولعلم الرياضـيات أصــوله المعرفية ونظر ياته وطرق تعليمه، التي ينبغي علن معلم الرياضـيات أن يمتلك المعتقدات والتصــورات الإبسـتمولوجية عن هذا العلم، كما يجب أن يمتلك المعرفة والمفاهيم الرياضية وطرق تقديمها وتعلميها؛ لماله تأثير جلي وواضح في طريقة تقديمه للمعر فة الرياضـية ومففاهيمها لدىن طلابه؛ فمن أجل نجاح معلم الرياضـيات في ممارسـته التدريسـية، وإكسـاب الطلاب البنية المعرفية الرياضـية بنجاح، يلزم ذلك امتلاك 
تصورات ومعتقدات إبستمولوجية حول طريقة بناء المعرفة والبنية المعرفية الريا ضية لطلابه، فمن أجل تمكن معلم الرياضيات من تدريس الرياضيات بنجاح لابد من الكشف عن طريقة تفكيره والتصــورات الإبسـتمولوجية التي يمتلك ها و ينطلق منها في بـناء المعر فة.

.(Longstreet,1990)

ومن المعتقدات التي يجب أن يمتلكها معلم الرياضيات المعتقدات الإبستمولوجية عن المعرفة المفاهيمية؛ لكونها من أصــول المعرفة الرياضـية وعلم الرياضـيات وبالذات ما يتعلق بالمفاهيم الرياضــية وطريقة تعلمها، لما تلعبه المعرفة المفاهيمية من دور في تعليم الرياضـيات ويناء المعرفة الريا ضية، فتعليم وتعلم المفاهيم الريا ضية لدى الطلاب يعتمد بـشكلٍ كبيرٍ علن معلم الرياضيات وتصور اته حول المفاهيم الرياضية وطرق اكتسابها وتعليمها، فقد أصبح من الضر-وري تناول المفاهيم الرياضـية وطبيعتها وطرق تعليمها وتعلمها، حيث ينبغي دراسـة وبحث موضــوع معرفة المفاهيم وطرق تعلمها من منظور إبسـتمولوجي؛ نظراً لتغير النظرة الإبسـتمولوجية للمفهوم الرياضي وطرق تعلمه بعد ظهور النظرية البنائية التي تفترض أن المتعلم يبني تعلمه بنفسه من خلال تفاعله مع البيئة التعليمية، ورؤية المعرفة بأنها عملية تكيف تحدث مـن خلال تنظيم الفرد للخبرات التي يتفاعل معها، وهذا شـكل المعامر الإبسـتمولوجية الشخصية لتعلم وتعليم المفاهيم الرياضية. (الشايع والقادري، 2012). إن امتلاكك معلم الرياضــيات للتصــورات والمعتقدات الإبســمولوجية حول طبيعة المفاهيم الريا ضية وطرق تعلمها وتعليمها سيساعد في سهولة إك سابها للطلبة وقدرتهم على اسـتيعابها وتطبيقها في مواقف خختلفة؛ لأن المفاهيم الرياضسية تسـاعد المتعلم علن التعلم الذاتي وتنمي التفكير وتســـل عملية التو اصـل الرياضي وتزيد من دافعية الطلبة نحو الرياضسيات، وتعد المفاهيم الرياضية في سلم أولويات تعلم الرياضيات وتعليمها ومن أهم أهداف تدريس الرياضيات في جميع المراحل الدراسية. (NCTM,2000). 
وتكمن أهمية امتلاك معلمي الرياضيات التصور رات و المعتقدات الإبستمولو جية لتعلم وتعليم المفاهيم في توجيه الممارسات التدريسية للمعلمين، فامتلاكهم لتصورات إبستمولوجية

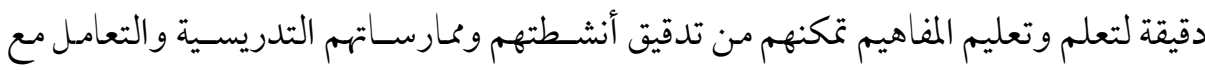
المستـجدات العلمية والتقنية وفق معايير دقيقة تنعكس علن طلبتهم في تعلمهم للمفاهيم

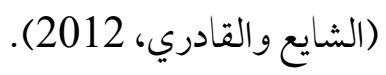
إن امتلاك معلم الرياضسيات التصـورات والمعتقدات الإبسـتمولوجية حول المفاهيم الريا ضية وطريقة تعلمها وتعليمها يقود إلن امتلاكه التصورات الإبستمولوجية حول المعرفة

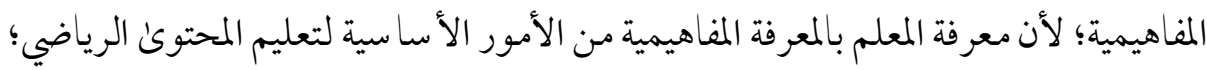
لكونها ستنعكس آثارها علن معرفة طلبته (2013, Jerry). وتتضـمن التصــورات الإبسـتمولوجية للمعر فة المفاهيمية فهم الأفكار والمفاهيم الريا ضية والاجراءات ومعرفة الحقائق الأ سا سية وتحديد أوجه الـشبه بين المفاهيم الريا ضية المختلفة وإنتاج الأمثلة للمفاهيم الرياضسية واستخدام الأشكال والرموز للتعبير عن الترابط بين المفاهيم الرياضية الرئيسة والفرعية (أبو عودة، 2018).

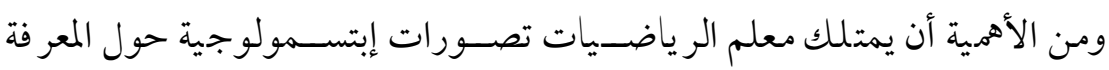
المفاهيمية وكيفية بناء المفاهيم الرياضـية بفهم ووعي، حيث يعد تطوير ممارسـات معلم

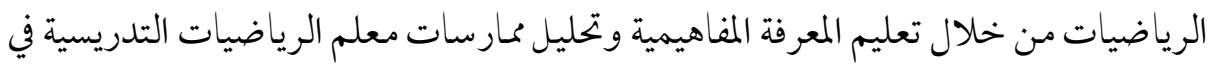

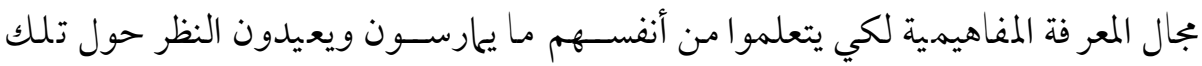
الممار سات؛ لأن معظم معلمي الريا ضيات يركزون علن استخدام أساليب التدريس التي تركز

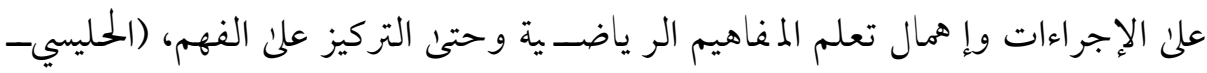
والسلولي،2016). 
ونظرًا لأهمية ممارسـات معلم الرياضـيات التدريسـية في إكسـاب المفاهيم الرياضـية وارتباطها بمعتقداتهم و تصــور اتهم الإبسـتمولو جية حول طبيعة تلك المفاهيم وطرق تعلمها وتعليمها، وتصوراتهم حول المعرفة المفاهيمية التي تؤكد فهـم المفاهيم الرياضية والتركيز على تقديمها بطرقٍ تســاعد المتعلم علن اسـتيعا بها وتطبيقها بعد التأكد من فهمها، فكان من الضر-وري التعرف علن مدىن امتلاكك معلمي الرياضـيات لتلك التصـورات الإبسـتمولوجية للمعرفة المفاهيمية؛ ونظرًا لندرة الدراسات -في حدود علم الباحث- التي تناولت التصورات الإبســمولوجية حول المعرفة المفاهيمية لدىن معلمي الرياضـيات بالتعليم العام، فسـيقوم الباحث بهذه الدراسة؛ لما يمكن أن تسهم به نتائجها في معرفة مدى امتلاكك معلمي الرياضيات للتصورات الإبر ستمولو جية للمعرفة المفاهيمية بها يساعد على تحسين خخرجات منظومة تعلم الرياضـيات وتعليمها في المملكة العربية السـعودية في ضــوء رؤية المملكة 2030 لتطوير التعليم.

مشكلة الدراسة: - n

يلاحظ في الميدان التربوي أن الملارسات التدريسية التي يتبعها معلمو الرياضيات هي أساليب وممارسات تقليدية تركز علن الإجراءات الروتينية الرياضية دون التعمق حول تنمية المفاهيم الرياضية، حيث يوجد إهمال للمعرفة المفاهيمية الرياضية والتركيز ينصب فقط على المعرفة الإجرائية (الحليسي، و السلولي، 2016)؛ ولذذا كان من الأهمية بمكان التعرف علن أسباب اهتحام معلمي الرياضيات بالمعرفة الإجرائية أكثر من التركيز على المعرفة المفاهيمية؛ وفي محاولة للكشف عن هذه الأسباب التي يمكن الوقوف علن تصورات ومعتقدات معلمي الرياضيات الإبستمولوجية حول المعرفة المفاهيمية الرياضية، فقد أثبتت بعض الدراسات وجود تباين بين معتقدات معلمي الرياضيات حول المفاهيم الرياضية واستيعاب طلابهم لها

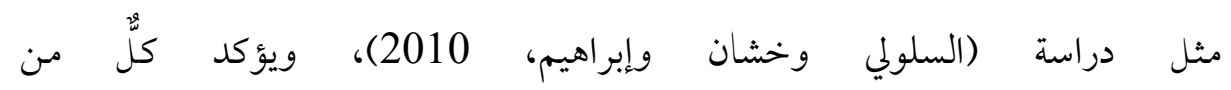


(Aspinwell\&Miller,1997) هي المعارف الرياضية المهمة؛ مـا يجعلهم يفتقدون الححد الأدنى من المعرفة المفاهيمية، وأظهرت نتائج دراسة القادري ومومني وقبلان ( 2010) إلى شيوع عدد من التصورات الإبستمولوجية الخاطئة لتعلم المفاهيم العلمية لدئ بعض المعلمين، وأظهرت نتائج دراسة ( Lising\&

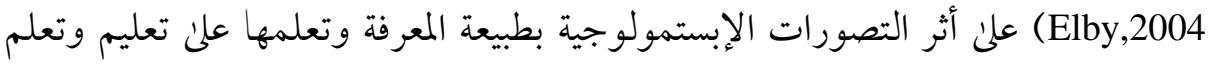

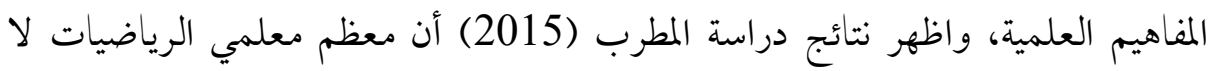
يمتلكون العمق الكافي من المعرفة الرياضية الذي يمكنهم من تجسيد وتثثل المفاهيم الرياضية

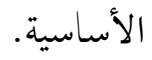

ميا سـبق يتضـح أهمية الكشـف عن التصـور ات الإبستمولوجية لمعلمي الرياضسيات بمر احل التعليم العام حول طبيعة المفاهيم الرياضسية والمعرفة المفاهيمية وطرق تعلمها؛ ونظرًا لندرة الدراسـات المحلية والعربية المتعلقة بالتصـورات الإبستمولو جية بشـكلٍ عامِّ والمتعلقة بالمعرفة المفاهيمية لمعلمي الريا ضيات بشكلٍ خاصِّ، وعليه تتحدد مشكلة الدرا سة بالسؤال الرئيسي والأسئلة الفرعية الآتية: بمئيس ما التصورات الإبستمولوجية لمعلمي الرياضيات حول المعرفة المفاهيمية في مراحل التعليم العام بمدينة حائز؟ ويتفرع منه التساؤلات الفرعية التالية: ما التصورات الإبستمولوجية لمعلمي الرياضيات حول المعرفة المفاهيمية ا المتعلقة بطبيعة المفهوم الرياضي؟ ما التصورات الإبستمولوجية لمعلمي الرياضيات حول المعرفة المفاهيمية المتعلقة في

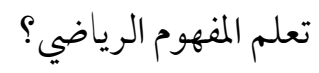


هل هناك فروق ذات دلالة إحصائية عند مستوى دلالة (0.05) بين متوسطات استجابات عينة الدراسة تعزي إلى المتغيرات (المرحلة التعليمية، المؤهل العلمي،

$$
\begin{aligned}
\text { أهداف الدراسة: } &
\end{aligned}
$$

تسعى الدراسة الحالية لتحقيق الأهداف الآتية:

الكشف عن التصورات الإبستمولوجية حول طبيعة المفهوم الرياضي لدىن معلمي

$$
\text { الرياضيات. }
$$

الكشف عن التصورات الإبستمولوجية حول تعليم المفهوم الرياضي لدئ معلمي

$$
\text { الرياضيات. }
$$

التعرف علئ الفروق بين وجهة نظر أفراد العينة حول التصور ات الإبستمولوجية حول المعرفة المفاهيمية والتي يمكن أن تعزئ للمتغيرات (المرحلة التعليمية، سنوات الخبرة،

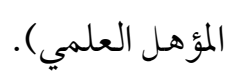

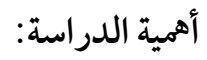

تكمن أهمية الدراسة من أهمية مو ضوعها الذي يتناول أصول المعرفة الرياضية وطرق

تعليمها، إضافة إلى إسهام هذه الدراسة بالآتي:

قد تفيد معلمي الرياضيات في التعرف علن تصوراتهم ومعتقداتهم الإبستمولوجية

للمعرفة المفاهيمية ومقارنتها بمحارساتهم التدريسية الحالية لها كمحاولة لتطويرها. يمكن أن تساعد معلمي الرياضيات في كشف تصور اتهم ومعتقداتهم الإبستمولوجية للمعرفة المفاهيمية الشائعة لديهم وتحديد مدئ اتساقها عن الرؤية المعيارية العلمية الصحيحة من حيث طبيعة المعرفة المفاهيمية وطرق تعلمها وتعليمها. 
توجيه نظر القائمين على تطوير مقررات الرياضيات لتضمين التصورات الإبستمولوجية للمعرفة المفاهيمية في دليل معلم الرياضيات.

قد تفيد القائمين علن برامج تدريب معلمي الرياضيات في تنمية تصورات ومعتقدات معلمي الرياضيات الإبستمولوجية حول المعرفة المفاهيمية وعلاقتها بأنماطهم التعليمية.

تعد هذه الدراسة من الدراسات القليلة- في حدود علم الباحث- التي تناولت التصورات الإبستمولو جية للمعرفة المفاهيمية في المملكة العربية السعودية.

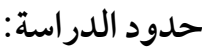

اقتصرت الدراســة على تناول موضوع التصورات الإبستمولوجية للمعرفة المفاهيمية المتعلقة بطبيعة المفهوم الرياضي وطريقة تعلمها، على عينة من معلمي الرياضيات في مراحل التعليم العام بمدينة حائل المملكة العربية السعودية، خلال الفصل الدراسي الثاني للعام 1440 2019/ مصطلحات الدراسة: - (20)

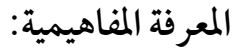
يعرف الحليسي والسلولي (2016) المعرفـــــة المفاهيمية بأنها المعرفة التي تتضمن فهم الأفكار والمفاهيم الرياضـية وإدراك العلاقات والترابطات بين المفاهيم الرياضــية والأفكار المختلفة التي تؤدي إلى فهم عميق للدرس. ويعرفها الباحث إجرائيّا بأنها جزءُمن المعرفة الرياضية تتعلق باستيعاب وفهم الأفكار والمفاهيم الرياضية وإجراءات تعليمها وفهم الترابط فيها بينها. 


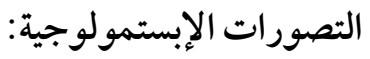

تعرف التصورات الإبستمولوجية بأنها الأفكار التي يحملها ويمتلكها الفرد عن المعرفة

العلمية واصلها وكيفية تكوينها و اكتسابها وتعلمها وتعليمها وتقويمها (هاني، 2015). ويعرف الباحث التصورات الإبستمولوجية إجرائَّا بأنها الآراء والأفكار التي يمتلكها معلم الريا ضيات حول المعرفة المفاهيمية الريا ضية وبنيتها وأصلها وكيفية تكوينها واكتسابها وتعليمها وتعلمها وتقويمها.

ويعرف الباحث التصــورات الإبسـتمولوجية للمعرفة المفاهيمية إجرائيّا: هي كل ما

يحمله معلم الرياضـيات من أداء و أفكار تتعلق بطبيعة المفاهيم الرياضــية وطرقت علميها وتعلمها وتقاس بالدرجة التي يجصـل عليها معلم الرياضـيات على أداة الدراسـة الاسـتبانة المعدة لقياس تصور اته الإبستمولوجية للمعرفة المفاهيمية في هذا الدراسة.

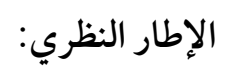

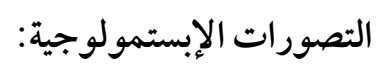

ظهرت الإبستمولوجية كمفهوم حديث يدور حول المعرفة وأصوها وتعريفها وهي مرتبطة بنظرية المعرفة، حيث يركا قاسم (2008) أنها كلمة مشتقة من كلمتين يونانية هي كلمة وتعني المعرفة و كلمة (Episteme)

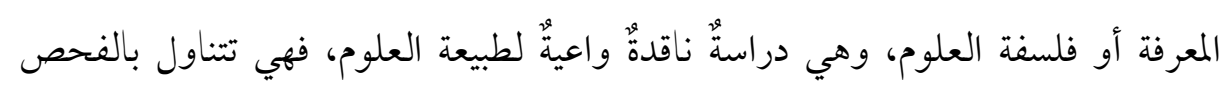
و التدقيق الأسس والمبادئ للبناء المنطقي لأي نسقِ علميٍٍ باستعال الاستقراء والاستنباط والكشف والتحقيق.

لقد تعامل بياجيه مع الإبستمولوجية كعلم لتكوين المعرفة، ونمائها ومعناها والوسائل التي تستخدم للانتقال من المستوى الأدنى للمعرفة إلى مستويات ومر احل عليا و إن دراسة علم تكوين المعرفة أو الإبستمولوجية يقتصر على البحث عن معنى المعرفة ونحائها وتقدمها عند 
الإنسان منذ الو لادة وحتى البلوغ، فقد نقل بياجيه الإبستمولو جية من مستوكئ البحث الفلسفي النظري إلن المستوئ العلمي المخبري القائم علن التجربة (سليم، 1985). ويقسم بياجيه الإبستمولوجية ( علم المعرفة أو علم تكوين المعرفة )إلى: 1- القسم الأول ويبحث في مبادئ العلوم ويهدف إلى تقويمها بهدف تفسير التطور الفكري للإنسان ووضع رؤية مستقبلية لهذا التطور. 2- القسم الثاني يبحث عن علم المعرفة وتطور المعارف عند الانسان من الولادة حتى

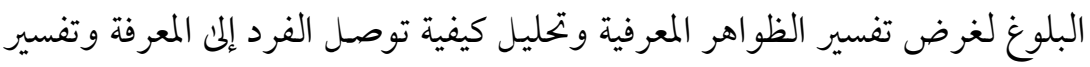

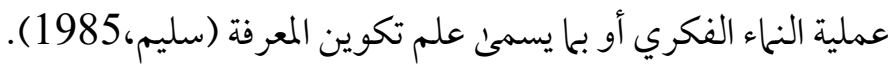
لقد تم ربط الإبستمولو جية بالتصــورات والمعتقدات حتى تتكون الرؤية الثاقبة لدين الفردو واتجاهاته حول طبيعة المعرفة؛ لأن دراسـة التصـور رات الإبسـتمولوجية بدأت من أعمال بياجيه حول الإبسـتمولوجية الوراثية حتى تطورت إلى بحوث المعتقدات حول المعرفة أو ما ذسمى المعتقدات الإبستمولوجية التي تعني بدرا سة كيفية تطوير الأفر اد لتصميلتهم المعرفية وتوظيفها في إدراك الع الهر المحيط وتحتوي المعتقدات أو التصـورات الإبسـتمولوجية علن العناصر الآتية: تعريف المعرفة، كيفية بنية المعرفة، وكيف يتم تصميم المعرفة، وأين تتم المعرفة، وكيف تحدث المعرفة (يمينة 2017). فينظر البعض إلى التصـورات الإبسـتمولوجية باعتبارها بجموعة المفاهيم والمعتقدات

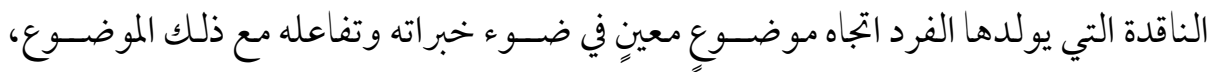
وتشكل هذه التصورات و المفاهيم إطارًا فكريًّا حول هذا الشيء (بدارنة، 2008).

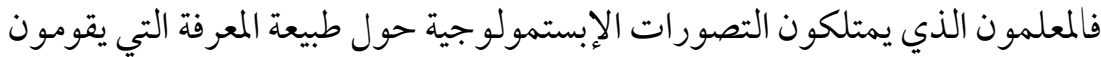
بتدريسها ستنعكس إيمباًّا علن أدائهم وممار ستهم التدريسية لتلك المعرفة، حيث أن المعتقدات أو التصورات الإبستمولوجية هي مفاهيم يمتلكها المعلمون حول طبيعة المعرفة وطبيعة عملية 
التعلم لتلك المعرفة، وتعكس تلك التصـورات وجهة نظر المعلم حول ماهية المعرفة، وكيف

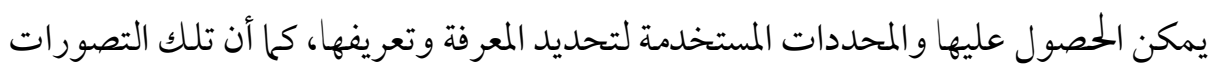
الإبستمولوجية تسهل التغير في عملية التعلم والتعليم وتحسينها (سعيد، 2001). ويرئ الباحث أن التصـور ات الإبسـتمولوجية لدنى المعلمين هي ججموعة من الأفكار والمتتقدات والقناعات التي يمتلكها المعلم لتنمية تفاعله المسـتمر مع المعرفة وإدراكه لطبيعتها

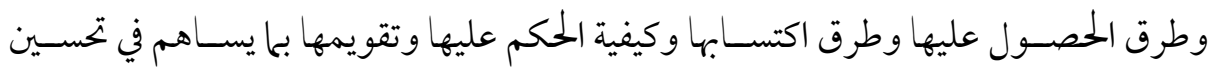
وتطوير تلك المعرفة وطرق تعليمها وتعلمها أثناء ممارساته التدريسية لها. أهمية التصورات الإبستمولوجية وأهمية دراستها:

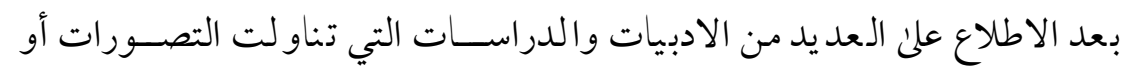

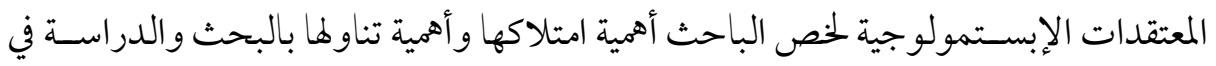
النقاط الآتية: (الشـايع والقادري، 2012)، (الطراونة، وخصساو نة، 2018)، (السـلولي وخشان وإبراهيم، 2010)، (الزعبي، الشرع، سلامات، 2012). 1- - تساعد علن إحداث تغيرات ايجابية في عملية التعليم والمتعلم. 2- - تساعد المعلمين علن تسهيل عملية تصميم التدريس وفهم كيفية التعامل مع طلابهم 3- تساهم في فهم السلوك التعليمي وأنماط التعلم لدئ الطلبة. 4- ت تطوير وتوجيه الممارسات التدريسية و التعليمية لدئ المعلم. 5- تكوين اتجاهات إيجابية نحو المعرفة وطرق تعلمها.

6- امتلاك المعلمين للتصورات الإبستمولوجية لتعلم وتعليم المفاهيم تمكنهم من تدقيق

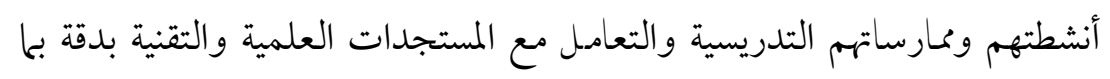
يسهم في تعلم طلبتهم لتلك المفاهيم. 7- معتقدات المعلمين نحو المعرفة تؤثر في معتقدات طلابهم نحوها. 
8- تلعب التصور ات دورًا في توجيه سلوكك المعلم داخل الصف وتحديد سلوك المتعلمين، فهي القوة في تشكيل هيكل ومحتوىن ممارساتهم في غرفة الصف وتؤثر في قرارات المعلم المتعلقة بالتخطيط و التدريس. 9- تساعد المعلمين في التبؤَ بمدى استيعاب طلابهم للمفاهيم وقدرتهم على التكفير.

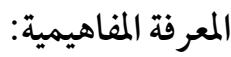

تتكون المعرفة الرياضية في أصولها من جزأين هما المعرفة المفاهيمية والمعرفة الإجرائية، فالمعرفة المفاهيمية تتعلق بالجانب النظري للمعرفة الرياضية الممثلة بمعرفة المفاهيم والتعميات والحقائق و النظريات الرياضسية ومعرفة طبيعتها وكيفية تعليمها وتعلمها وربطها بعلاقاتٍ فيما بينها، والمعرفة الإجرائية تتعلق بالجانب الإجرائي العملي والمهاري للمعرفة الرياضية أي كيف تسـتخدم تلك المعرفة المفاهيمية وتطبيقها في مرافق عملية حياتية وفي حل المشــكلات، حيث تتضمن المعرفة المفاهيمية كما يرى (الزهراني، 2014) الوعي بالمفاهيم الرياضية ومعرفة الفرد بالمفاهيم الريا ضية التي يتعامل معها و إدر اكه لمكوناتها وعلاقة تلك المفاهيم فيما بينها، والوعي بالمصطلحات الريا ضية وإدر اك معانيها العلمية الريا ضية، والوعي بالرموز الريا ضية وإدر اك معاني الرموز الرياضية المجردة. وتعرف المعرفة المفاهيمية بأنها اسـتيعاب الأفكار والمفاهيم الرياضـية الأسـاسـية من مصسطلحاتٍ ورموزٍ رياضسيةٍ وتعميماتٍ وعلاقاتٍ وإجراءات، وأسـاس المعرفة المفاهيمية هو معرفة المفاهيم الرياضـية التي تعد الأســاس المعرفي للمعرفة الرياضـية ومكوناتها التعميمات والنظريات والمهارات الرياضية، وبهذا الصدد يشير أبو أسعد (2010) أن المفاهيم الرياضية هي أسـاس تكوين الخوارزميات والمهارات الرياضــية وتؤدي لتكوين التعميات الرياضــية بأنو اعها والمسائل الرياضية. 
وحيث أن المفاهيم الرياضـية هي أسـاس مكونات البنية المعرفية الرياضـية كان من الأحرى تناو لها بالدراســة من حيث طبيعة المفاهيم الرياضـية وطرق تعليمها وتعلمهيا و اكتســابها، فيرئ (الشر-يف، 2016) أنه ينبغي أن تنال المفاهيم الرياضـية الاهتمام الاكبر بالبحث و التحليل من حيث معناها وتصسنيفها وطبيعتها وكيفية تدريسها، حتنى يتوصسلو المي أفضل الطرق و الاساليب لتعليمها واكسابها. وعليه ومن الأهمية البالغة التي تحتلها المفاهيم الرياضية سوف يقتصر الباحث هنا علن تناول جزء من المعرفة المفاهيمية وهو ما يتعلق بطبيعة المفهوم الرياضي وتعليمه.

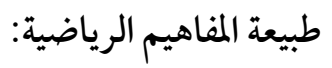

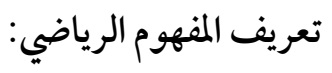
تعددت التعاريف التي تبنا ها الكتاب والتربويين في بجال تعليم الرياضـيات حول تعريف مو حد للمفهوم الرياضي يبرز طبيعته وخصـائصسـ؛ ومن هذه التعريفات ما ذكره الهويدي (2006) إن المفهوم الرياضي هو فكرة مجردة تشـــر إلى شيء له صـورة في الذهن وقد تعطي الفكرة المجردة اسـاً يدل عليها، وهو الوحدة البنائية للرياضـيات ولكل مفهوم مدلول مرتبط به. أمـا الشر-فيف (2016) فعرف المفهوم الرياضي بأنه الصـورة العقلية التي تتكون لدىن الفرد نتيجة خصائص مشتركة وتتألف من الاسم والدلالة اللفظية. أ ما أبوزيدنة (1997) يرى أن المفهوم الر ياضي عبارة عن فكرة أو بجمو عة افكار تسـتخدم لتبو يب مجمو عة من المدر كات وتتميز دائحاً بكلمة أو عبارة أو رمز لتصـبح اســاً 
ويعرف البا حث المفهوم الر ياضي بأ نه الصــورة الذهنية والمجردة لمجمو عة من الخـصائص الريا ضية المشتركة لمجموعة من الأ شياء و الأفكار الريا ضية لتعطي مدلو لاً معينًا يرتبط بتلك الأفكار ويعطي اسماً يطلق عليها دلالة علن المفهوم. مكو نات المفهوم الرياضي: يرىن كل من (الشـارف، 1997)، (الشرـيف، 2016)، (عبيد وآخرون، 2000)، (فرج الله، 2013) أن المفهوم الرياضي يتكون من ثلاثة مكو نات وعناصر هي: 1- فراغ المفهوم وتمثل جميع الحالات التي تتشابه بخصائص المفهوم الرياضي. 2- مصطلح المفهوم وهو الاسم أو الرمز الدال علن المفهوم والذي يطلق عليه في ضوء الخواص المشتركة. 3- محتوى المفهوم وتمثل الشروط الكافية للمفهوم الرياضي. أنواع المفاهيم الرياضية: هناك تصنيفات عديدة للمفاهيم الرياضية، ومنها: 1. المفاهيم الحسية والمفاهيم المجردة: المفاهيم الحسية هي المفاهيم المادية التي يمكن ملاحظتها أو مشاهدتها، والمفاهيم المجردة هي مفاهيم غير حسية، أي أنها المفاهيم

$$
\text { التي لا يمكن ملاحظتها ولا يمكن مشاهدتها. }
$$

2. مفاهيم متعلقة بالإجراءات: وهي التي تهتم بطرق العمل.

3. مفاهيم دلالية ومفاهيم وصفية: المفاهيم الدلالية هي التي تستخدم للدلالة على شيء ما، مثل: مفهوم العبارة الصائبة ومفهوم النسبة التقريبة، والمفاهيم الوصفية هي التي تحدد خصائص معينة تتصف بها بجموعة من الأشياء. 4. مفاهيم مفردة ومفاهيم عامة: المفاهيم المفردة هي التي بجموعة الإسناد لها بجموعة أحادية، و المفاهيم العامة هي التي مجموعة الإسناد لها تحوي علن أكثر من عنصر. 5. مفاهيم بسيطة ومفاهيم مركبة: المفاهيم البسيطة والمفاهيم المركبة. 
6. مفاهيم العلاقات: وهي التي تشتمل على علاقة معينة بين الأشياء. طبيعة تعلم وتعليم المفاهيم الرياضية: إن معرفة طبيعة المفاهيم الرياضـية جزءٌ مهـمّ من المعرفة المفاهيمية، والجزء الآخر هو معرفة كيفية تعليم وتعلم المفاهيم الرياضية وكيفية إكسابها للطلبة، ويجب أن يكون لدئ المعلم تصــورٌ واضــحْ وحول طرق تعليم وتعلم المفاهيم ليســـل عليه تقديمها للطلاب وتعديل ممار ساته التدريسية لها، وعليه سوف يتم ا ستعراض أهم الأفكار والإجراءات التي يجب على معلم الرياضـيات تصـورها وإدراكها عند تعلم وتعليم المفاهيم الرياضـية، وبعد اسـتعراض الأدبيات ذات العلاقة بتعليم المفاهيم الريا ضية فإن على المعلم إدراك التصورات التالية حول طبيعة تعلم وتعليم المفاهيم الرياضـية: (أبو عودة، 2018)، (الزهراني، 2014 )، (فرج الله،

$$
\begin{aligned}
& \text { 1- وضع مناقشات وشروحات غختلفة للمفهوم الرياضي } \\
& \text { 2- توظيف التكنولوجيا في تعميق الفهم للمفاهيم الرياضية. } \\
& \text { 3- دمج أنشطة رياضية مدرسية تتعلق بالمفاهيم الرياضية. }
\end{aligned}
$$

4- تحديد نوع المفهوم الرياضي قبل البدء بتعليمه وتحديد السمات الأساسية للمفهوم

$$
\text { الرياضي. }
$$

5- ضرب أمثلة إيجابية من المجموعة المرجعية للمفهوم مع أمثلةٍ سلبيةٍ من غير المجموعة

$$
\text { 6- ريد التعلم المرجعية مع تفسير كلتا الحالتين. }
$$

7- صياغة المفهوم بلغة واضحة تتضمن جميع الصفات الحرجة للمفهوم. 8- السير بطريقة الاستقر اء الاستباط عند تعليم المفهوم الرياضي.

$$
\text { 9- تقديم أمثلة منتمية وغير منتمية للمفهوم الرياضي. }
$$




$$
\text { 10-تقديم المفاهيم الرياضية المعقدة علن مر احل حتى يسهل اكتسابها. }
$$

11-صيانة تعريف المفهوم الرياضي بلغة واضحة تتضمن جميع السمات الحرجة للمفهوم

$$
\text { بحيث يتعلمها المتعلم بسهولة. }
$$

12- إتاحة الفرصة للتدريب علن المفهوم واستخدام في بناءمفاهيم رياضية اخرىن.

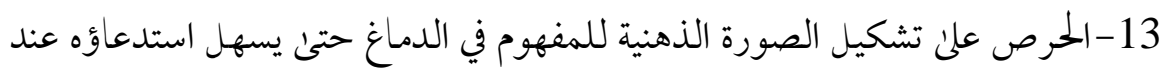

$$
\text { الحلاجة. }
$$

14-تقويم تعلم المفهوم الرياضي باستمرار للتأكد من مدئ اكتسابها من قبل الطلاب

$$
\text { ومدئ اكتساب خصائص المفهوم }
$$

15-تعزيز استجابات المتعلمين عند تعلم المفاهيم الرياضية حتى يتحقق التعلم الأمثل

$$
\text { للمفهوم الرياضي عند الطلبة. }
$$

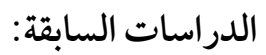

دراسـة القادري والمومني وقبلان (2010) اســهـدفت الكشـفـ عن التصــورات الإبسـتمولوجية لدىن معلم|ت الصـفوف الثلاثة الأولى لتعليم المفاهيم العلمية وعلاقتها

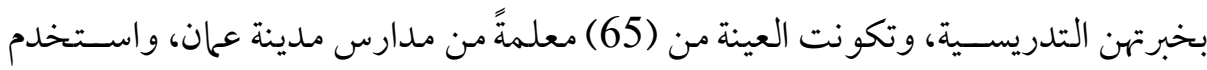

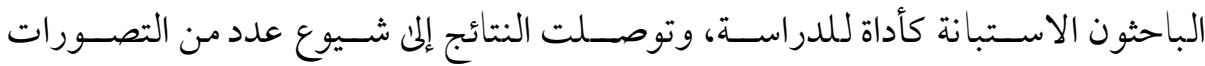
الإبسـتمولوجية الخطأ لدئ المعلمات، وأظهرت وجود علاق ته بين تصـورات المعلمات الإبستمولوجية ومستوئ خبرتهن التدريسية.

وكثـفت دراسـة ريان (2010) عن معتقدات معلمي الرياضسيات نحو تعليم وتعلم

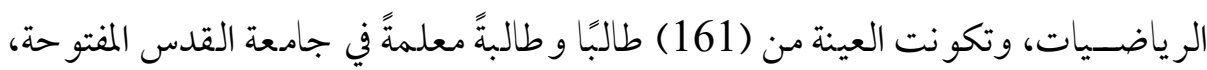
و أظهرت نتائج تطبيق مقياس المعتقدات أن الطلبة المعلمين تتفق معتقداتهم حول تعلم وتعليم الرياضيات مع التوجهات الحديثة.

http://dx.doi.org/10.29009/ijres.3.2.9 
دراسة القادري (2012) استهدفت الدراسة تقصي التصورات الإبستمولو جية لتعلم المفاهيم الفيز يائية لدى أعضـاء هيئة التدريس والطلبة بقســم الفيزياء في جامعة آل البيت، تكونت العينة من (11) عضسـو هيئة تدريس، (103) طالب وطالبة، وقد اسـتخدم الباحث الا ستبيان و المقابلة كأدوات للدرا سة، وقد أظهرت نتائجها أن أعضاء هيئة التدريس يملكون تصورات إب ستمولوجية لتعلم المفاهيم الفيزيائية في أربعة بجالات من أ صـل ستة، بينما كانت تصورات الطلبة الإبستمولوجية لتعلم المفاهيم الفيزيائية متوسطة. درا سة الشايع والقادري (2012) وقد استهدفت تقصي التصور ات الإبستمولوجية لتعلم وتعليم المفاهيم الفيز يائية لدى' أعضــاء هيئة التدريس في قســم الفيزياء بالجامعات السعودية والأردنية، تمثلت عينة الدراسة ب(46) عضو هيئة تدريس، وقد استخدم الباحثان،

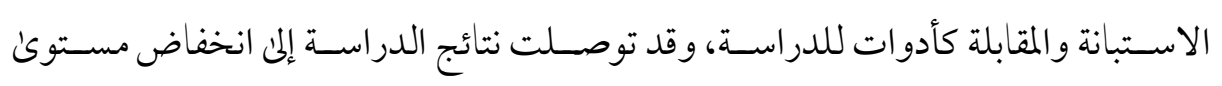
التصورات الإبستمولوجية لتعلم وتعليم المفاهيم الفيزيائية لدى أعضاء هيئة التدريس بشكل عام. واســة هـد فت دراســة الزعبي والشرـع (2012) التعرف علن أثر المعتقدات الإبستمولو جية لدىن طالبات جامعتي الأردنية والحسين بن طلال في أنحاط تعلمهم واتجاهاتهم العلمية، وتكونت العينة من (200) طالبة من طالبات معلم الصـف وتربية الطفل، وقد تم جمع المعلومات من خلال مقياس المعتقدات الإبسـتمولوجية ومقياس أنحاط التعلم ومقياس الاتجاهات العلمية، و أظهرت النتائج أن المعتقدات الإبســمولوجية الشـائعة لدئ الطالبات تختلف باختلاف الجامعة، وأن المعتقدات الإبستمولوجية تؤثر في الاتجاهات ولا تؤثر في أنحاط

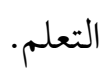
درا سة البر صان ور سمي (2017) استهدفت ا ستقصاء المعرفة الإبستمولو جية لدى معلمي ومعلمات الريا ضيات في المعرفة الريا ضية والمعرفة المتعلقة بكل من التقويم وأ ساليب 
التدريس، وتكونت عينة الدرا اسة من (146) معلمًا ومعلمةً للريا ضيات من الصف الثامن في

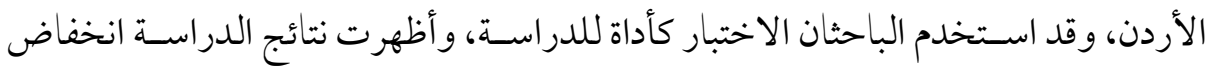

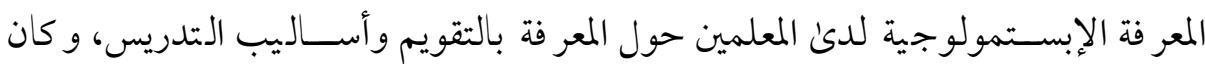
مستو اهم متوسطًا في تصور راتهم للمعرفة الرياضية.

درا سة يمينة (2017) ا ستهدفت الكشف عن العلاقة بين المعتقدات الإبستمولوجية

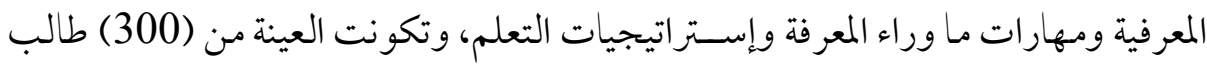

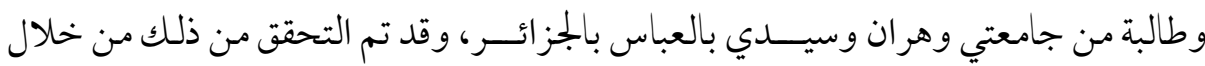

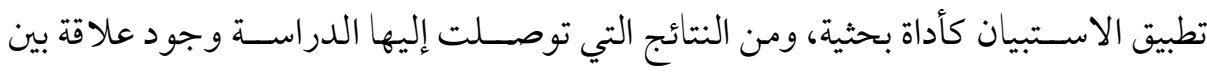
المعتقدات الإبستمولوجية المعرفية ومهار ات ما وراء المعرفة وإستراتيجيات التعلم. واستهدفت دراسة الطر اونة وخصاونة (2018) تقصي معتقدات معلمي الرياضيات

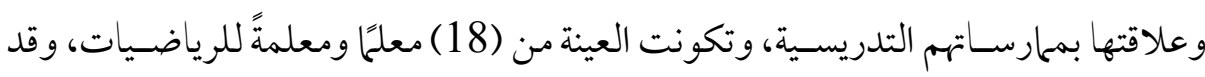
استخدم الباحثان استبانة المعتقدات وبطاقة ملاحظة، وأظهرت نتائج الدراسة تباين معتقدات المعلمين نحو الرياضـيات وتعلمها وتعليمها، وعدم توافق المعتقدات والمارسـات الثدريسـية

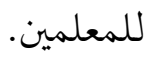

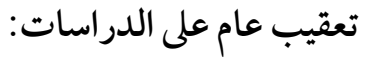
تناولت غالبية الدراسات استقصاء المعرفة الإبستمولوجية حول تعلم المفهوم لدىن

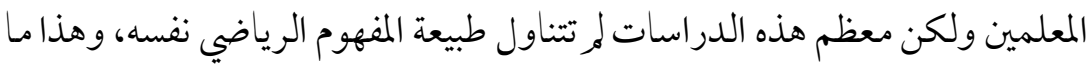
تناولته هذه الدراسة حيث تم تناول طبيعة المفهوم الرياضية نفسه بالإضافة إلى طبيعة تعلم وتعليم المفهوم. تباينت الدراسات السابقة من تناول المفاهيم فبعضها تناولت المفاهيم العلمية وبعضها المفاهيم الفيزيائية والأخرى المفاهيم الرياضية وهذا ما تناولته هذه الدراسة. 
اتفقت هذه الدراسة مع دراسة (القادري والمومني وقبلان، 2010) بو جود علاقة بين

$$
\text { التصورات الإبستمولو جية والخبرة التدريسية. }
$$

اتفقت هذه الدراسة مع دراسة (البرصان ورسمي، 2017)، في بعض النتائج حول المعرفة الإبستمولو جية لدى المعلمين حيث معظم مستو اهم كان متو سطًا في تصور اتهم للمعرفة الرياضية.

استخدمت معظم الدراسات السابقة الاستبانة كأداة رئيسة لجمع المعلومات وهناك من صمم مقياس للمعتقدات الابستمولوجية، وأيضاً بطاقة ملاحظة في حين كان هناك اختبار للكشف عن التصور ات لدئ الطلبة، وقد استفادت هذه الدر اسة من بناء أداتها من خلال الاطلاع علن هذه الدراسات. اهتمت الدراسات السابقة بالكشف عن التصورات الابستموبولجية لدئ المعلمين وقليل من هذه الدراسات تناول معتقدات الطلبة الإبستولوجية في حين هذه الدراسة تناولت المعلمين فقط. تم الاستفادة من أغلب هذه الدراسات في تحديد مشكلة الدراسة، وكذلك الإطار النظري، وبناء أداة الدراسة، وتحديد الأساليب الإحصائية. منهجية الدراسة وإجر اءاتها:

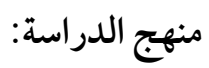
لتحقيق أهداف الدرا سة والإجابة عن أ سئلتها فقد عمد الباحث إلى ا ستخدام المنهج الوصفي الذي يعتمد علن دراسة الواقع أو الظاهرة كما توجد في الواقع، ويهتم بوصفها وصفًا دقيقًا ويعبر عنها تعبيرًا كيفيَّا أو تعبيرًا كمئًا. 
تكون بجتمع الدراسـة من جميع معلمي الرياضـيات في المراحل الثلاث (الابتدائية،

$$
\text { المتوسطة، الثانوية) بمدينة حائل المملكة العربية السعودية. }
$$

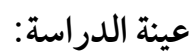

تكونت عينة الدراسـة من (33) معلمًا من معلمي الرياضـيات بمدينة حائل المملكة

العربية السعودية تم اختيارهم بطريقة عشو ائية طبقية حسب المرحلة التعليمية، وتم توزيعها وفق متغيرات الدراسة على نحو ما يوضحه الجدول التالي:

$$
\text { الجدول (1) توزيع أفراد عينة الدراسة وفقا لمتغيراتها }
$$

\begin{tabular}{|c|c|c|c|}
\hline النسبة & العدد & المتغرات & \\
\hline 21.2 & 7 & ملمرحلة الابتدائية & \multirow{4}{*}{ المرحلة التعليمية } \\
\hline 33.3 & 11 & المر حلة المتوسطة & \\
\hline 45.5 & 15 & المرحلة الثانوية & \\
\hline 100.0 & 33 & المجموع & \\
\hline 3.0 & 1 & أقل من 5 سنوات & \multirow{4}{*}{ سنوات الخبرة } \\
\hline 30.3 & 10 & من 5 سنوات إلى 10 سنوات & \\
\hline 66.7 & 22 & أكثر من 10 سنوات & \\
\hline 100.0 & 33 & المجموع & \\
\hline 78.8 & 26 & بكالوريوس & \multirow{3}{*}{ المؤهل الدراسي } \\
\hline 21.2 & 7 & ماجستير & \\
\hline 100.0 & 33 & المجموع & \\
\hline
\end{tabular}

يتضـح من الجدول أعلاه توزيع أفراد عينة الدراسـة حسبـ متغير المرحلة التعليمية،

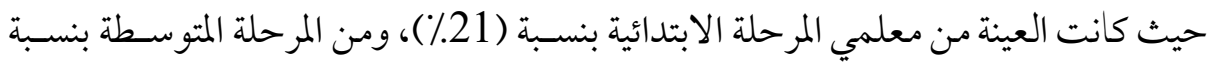

http://dx.doi.org/10.29009/ijres.3.2.9 
(33\%)، ومن المرحلة الثانوية بنســبة (46٪)، وحسـبـ متغير المؤهـل الدراسي، حيث كانت العينة من حملة مؤهل بكالوريوس بنسبة (79\%٪)، ومن ماجستير بنسبة (21\%)، و حسب متغير ســوات الخحمة، فقد بلغت نسـبة عينة الدر اسـة التي خبرتهم أقل من 5 سـنوات (3٪)، بينما بلغت نسبة عينة الدراسة التي خبرتهم من 5 سنوات إلى 10 سنوات (30٪)، بينما بلغت نسبة عينة الدراسة التي خبرتهم أكثر من 10 سنوات (67\%).

أداة الدراسة:

تحقيقًا لهدف الدراسـة والإجابة عن أسـئلتها فأن الأداة الأكثر ملاءمة هي الاسـتبانة، حيث قام الباحث بمر اجعة الأدب التربوي والدراسة السابقة ذات العلاقة بمو ضوع الدراسة وصياغة فقرات ومحاور الاستبانة بصورتها الأولية حيث تم تقسيمها إلى جزأين هما: الجزء الأول: وتضمن البيانات الأولية عن أفراد عينة الدراسة حسب متغيرات الدراسة الحالية وهي: (المرحلة التعليمية، المؤهل العلمي، سنوات الخبرة). الجزء الثاني: تكونت الاستبانة في صورتها الأولية من (56) فقرةً موزعةً على مجالين هما: المجال الأول: تصورات ومعتقدات معلمي الرياضيات الإبستمولوجية المتعلقة بطبيعة المفهوم الرياضي وتكون من (38) فقرة، المجال الثاني: تصورات ومعتقدات معلمي الرياضيات الإبستمولو جية حول تعلم المفهوم الرياضي، وتكون من (18) فقرة؛ حيث تم تصميم عبارات استبانة الدراسة وفقًا لمعيار التدرج الثلاثي لمقياس ليكرت لقياس درجة الموافقة حول تصورات معلمي الرياضيات الإبستمولوجية حول المعرفة المفاهيمية، وهو (موافق، محايد، غير موافق) بحيث تعطى درجة الاستجابات الدرجات الآتية (3، 2، 1) علن الترتيب. صدق أداة الدراسة

تعد الأداة البحثية صـادقة إذا قاسـت الظاهرة التي أعدت لقياسـها فعلاً وليس شـئًا آخر، و عليه فقد اعتمد الباحث للتحقق من صدق الاستبانة علن طريقتين: 
بعد الانتهاء من إعداد الاستبانة وبناء فقراتها بصورتها الأولية، تم عرضها علن مجموعة من المحكمين والخبراء المختصـين و قام الباحث بإجر اء التعديلات التي اتفق عليها أكثر من (\%) (80)

\section{ثانياً: صدق الاتساق الداخلي لأداة الدراسة:}

تم حسـاب صــدق الاتســاق الداخلي للاسـتبيان، من خلال اسـتخدام معامل ارتباط "بير سون" لحساب معامل الارتباط بين درجة كل محور مع الدرجة الكلية للا ستبيان، وذلك للتأكد من مدى تماسك وتجانس محاور الا ستبانة، فكانت معاملات الارتباط كما هي مو ضحة

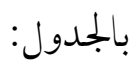
جدول ( 2 ) معامل ارتباط بيرسون بين درجة محاور الاستبانة والدرجة الكلية

\section{معامل الارتباط

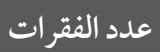

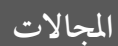

$94.0 * *$

38

$$
\text { المحور الأول: تصورات ومعتقدات معلمي الرياضيات }
$$

$$
\text { الإبستمولو جية المتعلقة بطبيعة المفهوم الرياضي }
$$

$91.0 * *$

18

$$
\begin{aligned}
& \text { المحور الثاني: تصورات ومعتقدات معلمي الرياضيات }
\end{aligned}
$$

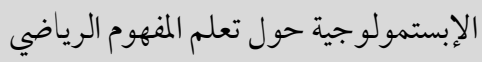

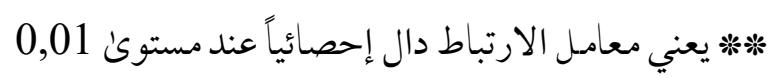

يتضـــح من الجمدول السـابق أعلاه أن معاملات ارتباط بيرســون بين درجة كل محور والدرجة الكلية للاستبيان مرتبطة ارتباطاً ذا دلالة إحصائية مع الدرجة الكلية للاستبانة حيث كانت جميع معاملات الارتباط للمحاور دالة إحصـائيّا، مما يثبت صـدـ الاسـتبيان ومحاوره وأيضًا حُســب صــدق الاتسـاق الداخلي لكل فقرة من فقرات المحاور الاسـتبيان من خلال 
حسـاب معامل ارتباط بيرسـون بين درجة كل فقرة والدرجة الكلية لمحورها، كما يوضـحها

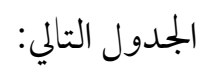

$$
\text { جدول (3) معامل ارتباط بيرسون لفقرات الاستبيان }
$$

\begin{tabular}{|c|c|c|c|c|c|c|c|c|c|c|c|}
\hline \multicolumn{4}{|c|}{ صدق فقرات المجال الثاني } & \multicolumn{8}{|c|}{ صدق فقر ات المجال الأول } \\
\hline معامل الارتباط & 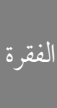 & معامل الارتباط & ل الفقرة & الارتباط & الفقرة & معامل الارتباط & ل لفقرة & معامل الارتباط & 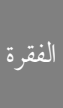 & معامل الارتباط & 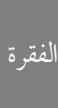 \\
\hline$* * 0.72$ & 11 & $* * 0.58$ & 1 & $* 0.27$ & 31 & $* 0.37$ & 21 & $* 0.24$ & 11 & $* * 0.84$ & 1 \\
\hline$* * 0.76$ & 12 & $* 0.34$ & 2 & $* 0.32$ & 32 & $* * 0.79$ & 22 & $* 0.35$ & 12 & $* 0.39$ & 2 \\
\hline$* * 0.54$ & 13 & $* 0.32$ & 3 & $* 0.33$ & 33 & $* 0.37$ & 23 & $* 0.39$ & 13 & $* 0.35$ & 3 \\
\hline$* * 0.70$ & 14 & $* * 0.49$ & 4 & $* * 0.67$ & 34 & $* * 0.66$ & 24 & $* 0.22$ & 14 & $* * 0.76$ & 4 \\
\hline$* * 0.73$ & 15 & $* * 0.81$ & 5 & $* * 0.82$ & 35 & $* 0.28$ & 25 & $* 0.35$ & 15 & $* * 0.54$ & 5 \\
\hline$* * 0.57$ & 16 & $* * 0.70$ & 6 & $* * 0.80$ & 36 & $* 0.21$ & 26 & $* * 0.57$ & 16 & $* 0.30$ & 6 \\
\hline$* * 0.50$ & 17 & $* * 0.60$ & 7 & $* * 0.49$ & 37 & $* * 0.73$ & 27 & $* 0.22$ & 17 & $* 0.38$ & 7 \\
\hline \multirow[t]{3}{*}{$* 0.25$} & 18 & $* * 0.77$ & 8 & $* 0.37$ & 38 & $* 0.30$ & 28 & $* 0.24$ & 18 & $* 0.32$ & 8 \\
\hline & & $* * 0.80$ & 9 & & & $* 0.26$ & 29 & $* 0.28$ & 19 & $* 0.28$ & 9 \\
\hline & & $* * 0.67$ & 10 & & & $* 0.24$ & 30 & $* 0.25$ & 20 & $* 0.28$ & 10 \\
\hline
\end{tabular}

*عني معامل الارتباط دال إحصائياً عند مستوى دلالة 0.05.، ق*مت يعني معامل الارتباط دال إحصائياً عند مستوى 0,01

يتضح من الجدول الـسابق أعلاه أن معاملات ارتباط بير سون فقرات الا ستبيان دالة

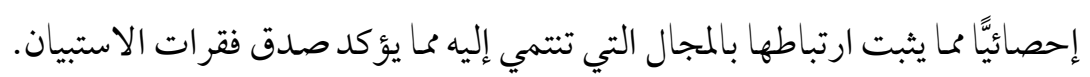

\section{ثبات أداة الدراسة}

تم اسـتخدام معادلة ألفا كرونباخ للتأكد من ثبات أداة الدراسـة فكانت معاملات الثبات لكل بجال من بجالات الاستبانة والثبات الكلي للاستبيان كما هو موضح بالجدول التالي: جدول (4) معامل ألفا كرونباخ لثبات الاستبيان ومحاوره

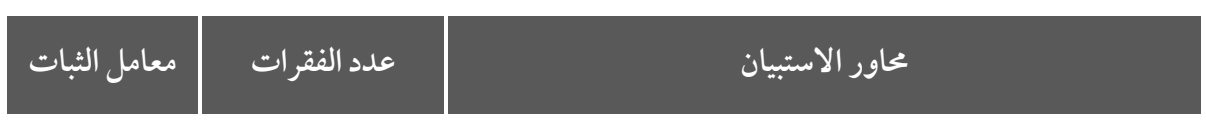




\begin{tabular}{|c|c|c|}
\hline 0.80 & 38 & المحور الأول: تصورات ومعتقدات معلمي الرياضيات \\
\hline 0.84 & 18 & المحور الثاني: تصورات ومعتقدات معلمي الرياضيات \\
\hline 0.89 & 56 & المجموع \\
\hline
\end{tabular}

يتضـح من الجمدول الســابق أعلاه أن معامل ثبات الاســبيان وبجالاته يتمتع بثبات

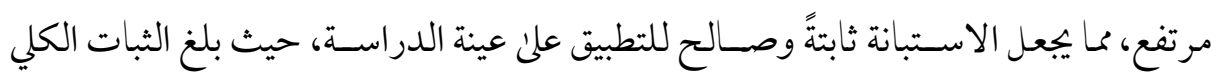
للاستبيان 0.89 وهي قيمة مرتفعة للثبات. الأداة في صورتها النهائية بعد التأكد من صدق وثبات الاستبانة أصبحت أداة الدراسة جاهزة للتطبيق بصورتها النهائية، حيث بلغ عدد عبار ات الاسـتبانة في صـورتها النهائية (56) فقرةً موزعةً على مجالين. ولغرض تفسير النتائج تم وضع المحكك الموضح في الجمدول الآتي: جدول (5) محك تفسير نتائج فقرات الاستبيان

\begin{tabular}{|c|c|}
\hline درجة الموافقة & الفئة \\
\hline ضعيفة & $1-1.66$ \\
\hline متوسطة & $1.67-2.32$ \\
\hline كبيرة & $2.33-3$ \\
\hline
\end{tabular}

SPSS الأساليب الإحصائية: تم استخدام الأساليب الإحصائية التالية من خلال البرنامج وهي: معامل ثبات ألفا كرونباخ، معامل ارتباط بيرسون، التكرارات والنسب المئوية، المتوسطات الحسابية والانحر افات المعيارية، واختبار ت لعينتين مستقلتين، واختبار مان وتني، واختبار كروسكال والس. 


\section{عرض نتائج الدراسة وتفسيرها ومناقشتها:}

الإجابة عن السؤال الأول الذي نص: ما تصورات ومعتقدات معلمي الرياضيات

$$
\text { الإبستمولوجية المتعلقة بطبيعة المفهوم الرياضي؟ }
$$

للإجابة عن السؤال الأول تم استخدام المتوسط الحسابي والانحر اف المعياري لدرجة

مو افقة عينة الدراســة علن در جة فقرات المجال الأول، ورتبت الفقرات حســب المتوســط

$$
\text { الحسابي، ويتضح ذلك في الجلدول الآتي: }
$$

جدول ( 6) المتوسطات والانحر افات المعيارية لآراء عينة الدراسة حول تصورات ومعتقدات معلمي الرياضيات الإبستمولوجية المتعلقة بطبيعة المفهوم الرياضي

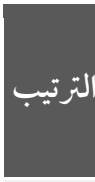

لمرجة الموافقة

\begin{tabular}{|c|}
\hline \\
\hline لحسابي \\
\hline
\end{tabular}

|الانحراف|
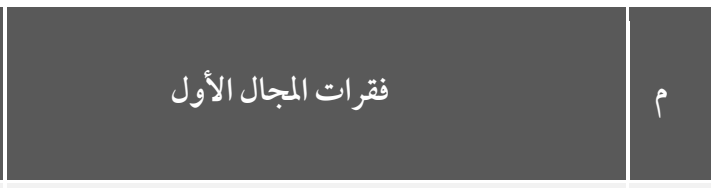

$1 \quad$ عالية

0.17

2.97

لا يمكن أن يقوم فكرٌ رياضي بدون مفاهيم رياضية.

17

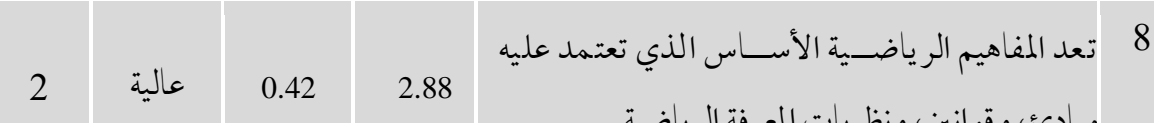 مبادئ، وقو انين، ونظريات المعرفة الرياضية.

\begin{tabular}{l|l|l|l|}
\hline & & & \\
\hline & 0.33 & 2.88 \\
\hline
\end{tabular}

19 قد نكون الرموز الرياضـية أداة توضـيحية للمفاهيم

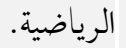

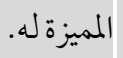

\begin{tabular}{l|l|l|l|}
\hline 5 & 0.42 & 2.79
\end{tabular}

ترتبط بعض الرموز الرياضـية فيها بينها في إطار المفهوم الواحد 


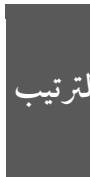

\section{درجة \\ المو افقة}

6

0.61

0.44

0.45

8

0.45

90.53

2.70

2.76

2.73

33 المفاهيم الرياضية على مستوىن الموضوع الواحد مترابطة مع بعضها البعض.

1

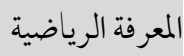

7

28 معظم المفاهيم الر ياضـية ترتبط بعلا قات مع مفاهيم

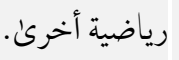

ترتبط المفاهيم الرياضـية في خختلف فروع ومواضـيع

عالية 0.53

2.70

$$
\text { الرياضيات مع بعضها البعض. }
$$

31 العلا قة تكاملية بين المفاهيم في مقرر الر ياضــيات

$11 \quad 0.48$

2.67

والمفاهيم في المقر رات الدراسية الأخرى' ذات العلاقة.

للمففاهيم الر ياضــية أنواع مثل: البسـيطة والمركبة.

12

$$
\text { عالية }
$$

0.48

2.67

$$
\text { الأولية والثانوية والمحسوسة والمجردة. }
$$

$13 \quad 0.66$

2.58

قد تكون التجربة الحسية مصدر للمفاهيم الرياضية

12 


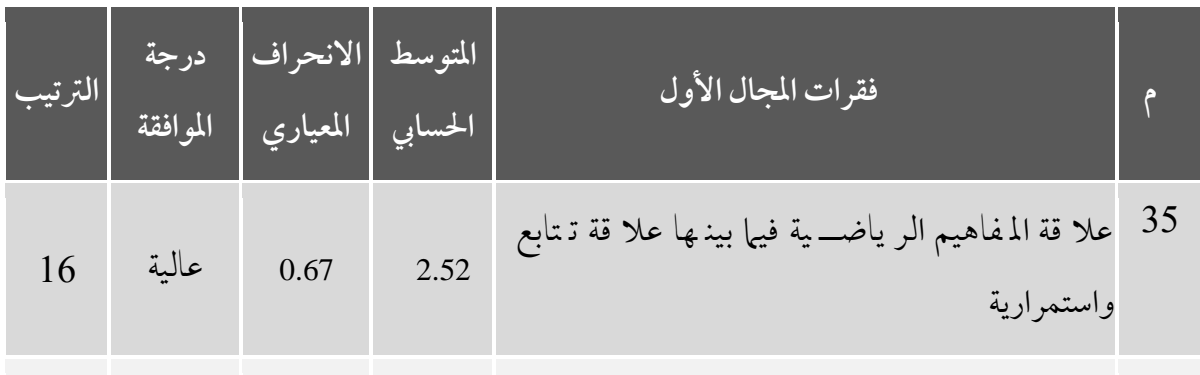

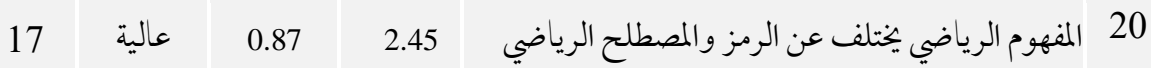

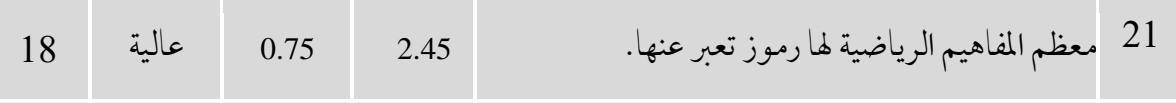

$19 \quad 0.71$

2.45

36 ينظر إلى المحتوى الر ياضي كبهناء محكم الترابط والاتصال، ووحدة البناء الأساسية هي المفاهيم

\begin{tabular}{|c|c|c|c|c|}
\hline 20 & عالية & 0.79 & 2.39 & اكتساب المفاهيم الرياضية مرتبط بالأمثلة المنتمية وغير \\
\hline
\end{tabular}

9 لكل مفهوم رياضي مقابل حسي في العالر الطبيعي $2.36 \quad 0.55 \quad 21 \quad$ لمالية 210

25 يمكن تمثيل المفهوم الر ياضي من خلال الشــلكل $2.33 \quad 2.74$

34 تعتبر المفاهيم الريا ضية هي الـ ضامن الأ ساسي للترابط

بين موضسوعات الرياضـيات نفسـها فقط وليس بينها 2.33 م 230.96

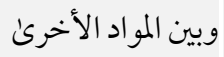

22 المصطلحات الرياضية هي مفاهيم رياضية ثابتة. $2.30 \quad 0.73 \quad$ متوسطة 24

المترابطة 


\begin{tabular}{|c|c|c|}
\hline الترتيب & الموافقة & الالنحراف \\
\hline 26 & متوسطة & 0.83 \\
\hline
\end{tabular}

0.44

0.83

0.86

متوسطة 30.82

0.770
$32 \quad 0.93$

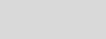

0.82

\begin{tabular}{l|l|l} 
& & \\
& &
\end{tabular}

2.12

2.24

2.24

\section{فقر ات المجال الأول}

4 قد تكون المفاهيم الر ياضـية فطر ية لكن الأكثر منها

6 لعملية التشكل والتجرد

$$
\text { معظم المفاهيم الرياضية مجردة. }
$$

10 المفاهيم الرياضية محددة وثابتة ومطلقة غير قابلة للتغيير

$$
\text { و التجديد. }
$$

18 14 المفاهيم الرياضـية يمكن التحقق من صستها بالبرهان

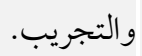

\section{6}




\begin{tabular}{|c|c|c|c|c|c|}
\hline 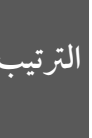 & 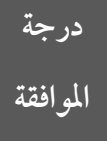 & | الانحراف & المتوسط & فقر ات المجال الأول & p \\
\hline 36 & متوسطة & 0.79 & 1.94 & المفهوم الرياضي ليس شيئاً محسوساً قائماً في الو اقع & 13 \\
\hline 37 & متوسطة & 0.48 & 1.79 & المفاهيم لا توجد في العالر الحسي لأنه نسبي ومتغير علن & 11 \\
\hline 38 & 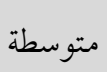 & 0.82 & 1.79 & يمكن التعبير عن المفهوم الرياضي بالمصطلح الرياضي. & 24 \\
\hline لية & & 0.24 & 2.42 & المتوسط العام للمحور & \\
\hline
\end{tabular}

يتضح من الجحدول الـ سابق أعلاه المتو سطات الحسبابية والانحرافات المعيارية لدرجة

مو افقة عينة الدراسـة حول تصـورات ومعتقدات معلمي الرياضسيات الإبسـتمولوجية حول

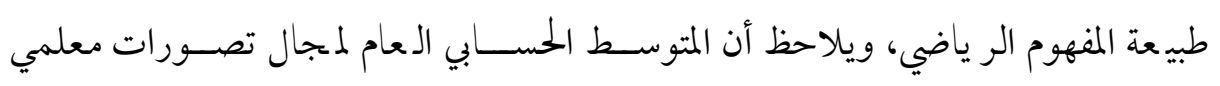
الرياضسيات الإبستمولو جية حول طبيعة المفهوم الرياضي بلغ 2.42 بدرجةٍ عاليةٍ، وهذا يدل علن أن معلمي الرياضيات لديهم تصورات إبتسمولوجية عالية حول طبيعة المفهوم الرياضي، و قد يعود هذا إلى الاهتمام التي توليه مشــاريع تعليم الرياضــيات والعلوم والتي ركزت في ســواتها الأخيرة علن الاسـتيعاب المفاهيمي في الرياضـيات وتوجيه مراكز التدريب بالمناطق لإق قامة دورات وحقائب في هذا المجال؛ نظراً لترســخ إدراك أهمية المفهوم الرياضي كجزء أساسيِّ في البنية المعرفية الرياضية والمعرفة المفاهيمية، ويتضح من الجمدول السابق أعلاه أيضًا أن المتوســطات الحســابية لفقرات المحور تراو حت ما بين (1.79 - 2.97) و كانت در جة المو افقة متباينة ما بين العالية والمتوسـطة ولم توجد فقرة درجة مو افتتها قليلة، وهذا دلالة على امتلاك معلمي الرياضـيات التصــورات الإبسـتمولو جية للمفاهيم الرياضــية، ولمزيد من التفصيل و إلقاء الضوء علن فقرات المجال الأول للتعرف علن أعلى الفقرات التي حصلت علن 
أعلان متوسـط ودرجة مو افقة حيث حصـلت الفقرة السـابعة عشر-ة علن المرتبة الأولن والتي

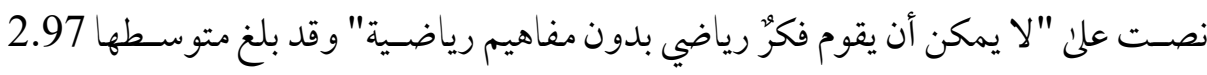

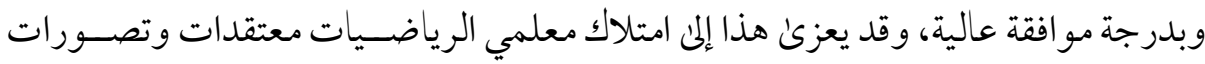

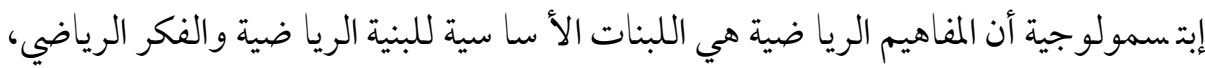

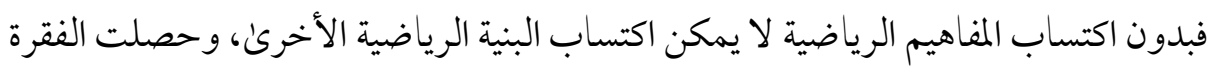

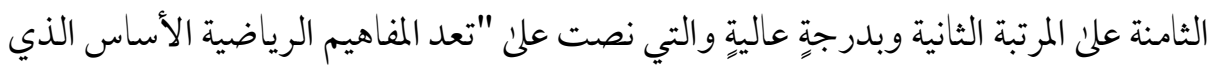

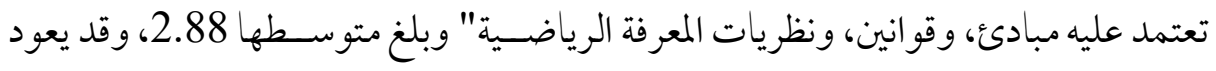

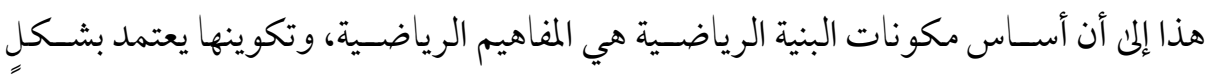

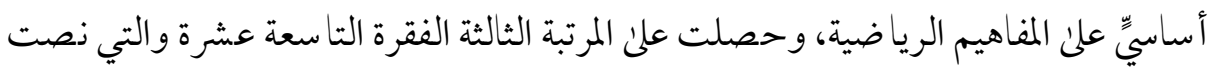

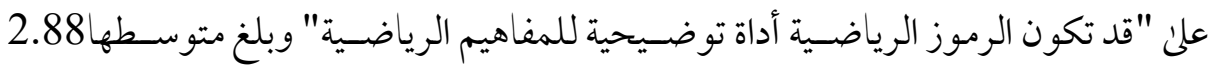

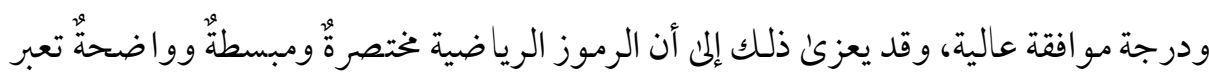

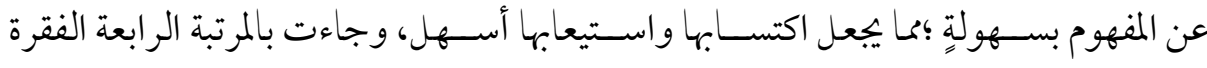
الساد سة عشرة والتي زصت علن "المفهوم الرياضي يتكون من بجموعة من الخصائص المميزة

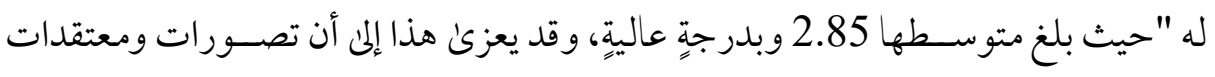

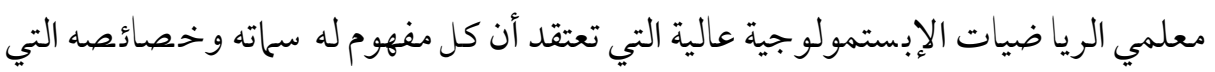

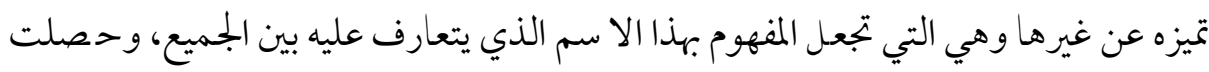

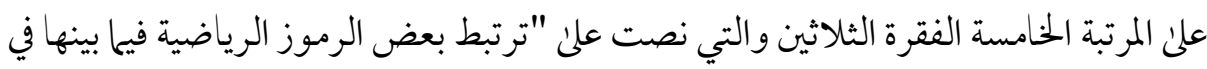

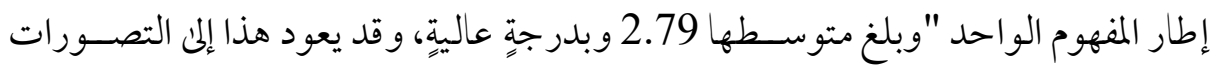

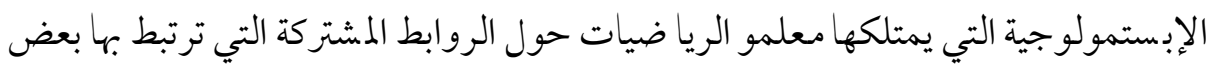

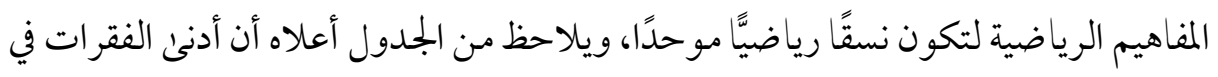
المجال الني حصلت علن أقل متوسط ودرجة هي الفقرة الثالثة عشر والتي نصت علن "المفهوم 
الرياضي ليس شيئًا محسو سًا قائًا في الو اقع "وعلنّ متو سط 1.94 ودرجةٍ متو سطةٍة، وقد يعود

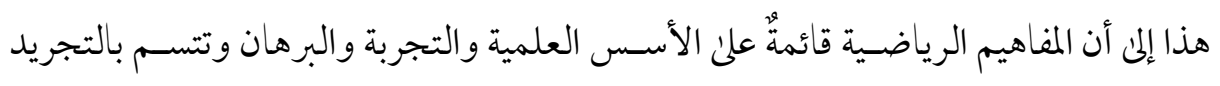

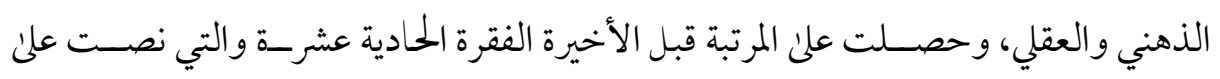

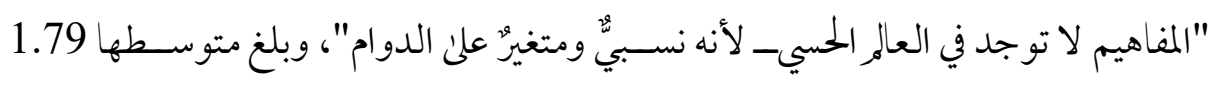
وبدرجة متوسطةة، وهذا يدل علن امتلاك معلمي الرياضسيات التصـور حول نسـبية المفاهيم

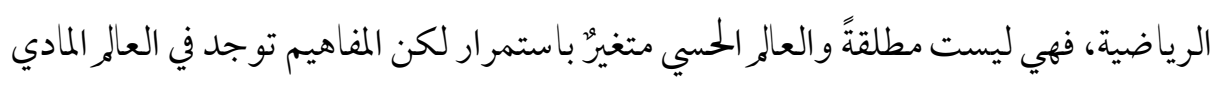

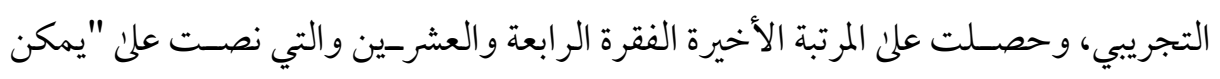

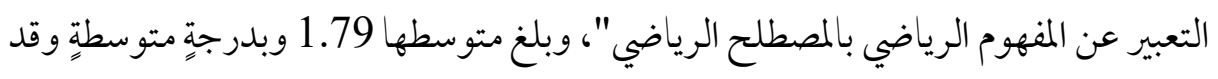

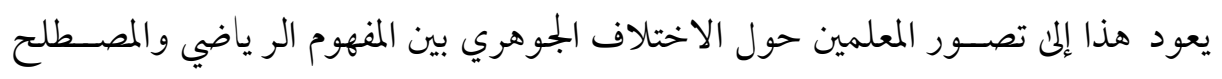
الرياضي. التتائج المتعلقة بالسؤال الثاني الذي نص: ما تصورات ومعتقدات معلمي الرياضيات الإبستمولوجية حول تعلم المفهوم الرياضي؟

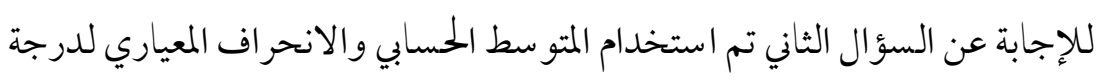

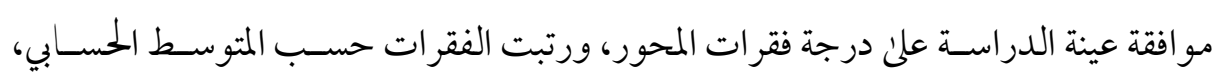
ويتضح ذلك من الجدول التالي: 


$$
\begin{aligned}
& \text { جدول (7) المتوسطات والانحر افات المعيارية لآراء عينة الدراسة حول تصورات ومعتقدات معلمي } \\
& \text { الرياضيات الإبستمولوجية حول تعلم المفهوم الرياضي } \\
& \text { الترتيب } \\
& \text { المتوسط } \\
& \begin{array}{l|l|l|}
\hline & 0.39 & 2.82
\end{array} \\
& \text { جميع المفاهيم الرياضية قابلة للتعلم لكن بدرجات } \\
& \text { متفاوته } \\
& \text { عالية } \\
& 0.45 \\
& 2.73 \\
& \text { فقرات المحور الثاني } \\
& \text { p } \\
& \begin{array}{l|l|l|}
3 & 0.54 & 2.67
\end{array} \\
& \text { إجراء المهارات الرياضية يعتمد علن استيعاب المفاهيم } \\
& 17 \\
& \text { ترتبط بعض المفاهيم الرياضية لتشكل مفهوم رياضي } \\
& 5 \\
& \begin{array}{|l|l|l|l|}
\hline 4 & \text { ع } & 0.56 & 2.58
\end{array} \\
& \text { يساعد تعلم المفاهيم الرياضية علن الفهم العميق لطبيعة } \\
& \text { علم الرياضيات. } \\
& \text { اكتساب بعض المفاهيم الرياضية يسهل اكتساب }
\end{aligned}
$$

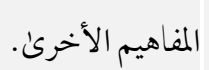

$$
\begin{aligned}
& \text { أن تعلم المفاهيم الرياضية الخاصة بالرياضيات } \\
& \text { ضروري للنجاح فيها } \\
& \begin{array}{l|l|l|l|}
\hline 8 & 0.90 \quad 2.45 \\
\hline
\end{array} \\
& \text { و وم نفسه و درجة تعقيده يؤثر ان علن قابلية تعلم المفهوم } \\
& \text { الرياضي }
\end{aligned}
$$

\section{http://dx.doi.org/10.29009/ijres.3.2.9}




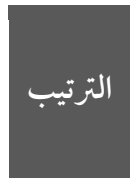

المسابي

\section{فقرات المحور الثاني}

متوسطة 10.85

2.33

2

كتساب التعلم المفاهيمي من خلال حل التطبيقات 2.33 | 2.890 .890

120.74

2.33

يرتبط تعليم المفاهيم الرياضية بالقدرة علن تفسير 16

\begin{tabular}{|l|l|l|}
13 & 0.88 & 2.30 \\
\hline
\end{tabular}

ليس شرطاً أن اكتساب المعرفة المفاهيمية يؤدي إلى

$$
\text { اكتساب المعرفة الإجر ائية. }
$$

| 0.80

2.27

تعلم المفاهيم الرياضية تدخل في حل مشكلات تو اجهنا في حياتنا اليومية

| 15

اكتشاف التعميات الرياضية يرتبط مباشرة بتعلم 18 المفاهيم الرياضية ذات العلاقة.

16

0.93

2.12 3

$17 \quad$

0.91

اكتساب المعرفة الإجرائية يؤدي بالتأكيد لاكتساب

2.09

المعرفة المفاهيمية

11 التعلم الإجرائي هو بمثابة تطبيق للتعلم المفاهيمي 2.03 
يت ضح من الجمدول الـسابق أعلاه المتو سطات الحسابية والانحرافات المعيارية لدرجة مو افقة عينة الدراســة حول تصـورات ومعتققدات معلمي الرياضسيات الإبسـتمولوجية حول تعلم المفهوم الرياضي، ويلاحظ أن المتوسط الحسابي العام لمجال تصورات معلمي الرياضيات الإبستمولوجية حول تعلم المفهوم الرياضي بلغ 2.41 بدرجةٍ عاليةٍ، وهذا يدل على أن معلمي الريا ضيات لديهم تصورات ابتسمولوجية عالية حول ا ستراتيجيات وأ ساليب تعليم وتعلم المفاهيم الرياضــية، وقد يعود هذا إلى امتلاكك معلمي الرياضـيات عينة الدراسـة تصـورات ومعتقدات ابتسمولو جية عالية حول أهمية اكتساب واستيعاب المفهوم الرياضي كجزءٍ أساسيٍ لتعلم واكت ساب المعرفة المفاهيمية، ويتضح من الجلدول أعلاه أيضًا أن المتو سطات الحسابية لفقرات المجال الثاني تراوحت ما بين (2.03 - 2.82) و كانت در جة المو افقة متباينةً مـا بين العالية والمتوسـطة، ولم تو جد فقرة در جة مو افقتها قليلةٌ و هذا دلالةٌ علن امتلاكك معلمي الرياضيات التصورات الإبستمولوجية لتعلم وتعليم المفاهيم الرياضية، ولمزيد من التفصيل لعرض نتائج فقر ات المجال الثاني للتعرف على أعلى الفقرات التي حصـلت علن أعلى متوسط ودرجة مو افقة، ويتضـح من الجمدول السـابق أعلاه أن الفقرة السـابعة حصـلت المرتبة الأولى والتي نصــت على "جميع المفاهيم الرياضـية قابلة للتعلم لكن بدر جات متفاو تة "وقد بلغ متوســطها 2.82 و بدر جة مو افقة عالية، و قد يعزىن هذا إلى امتلاك معلمي الرياضـيات معتقدات وتصورات ابتسمولوجية تتعلق بطبيعة تعلم وتعليم المفاهيم الريا ضية التي تختلف باختلاف نوع المفهوم الرياضي فكل مفهوم يتطلب طريقة خاصسة بتعليمه، وحصـلت الفقرة الخامسة علن المرتبة الثانية وبدرجة عالية والتي نصت "ترتبط بعض المفاهيم الرياضية لتشكل مفهوم رياضي واحد" وبلغ متو ســطها 2.73، وقد يعود هذا إلى أن أسـاس مكو نات بعض سر المفاهيم الرياضـية تنتج من خلال الترابط بين عدة مفاهيم رياضـية مثال لذلك مفهوم الدالة المثلثية هي مرتبطة بمفهوم الدالة والمثلث، وحصـلت علن المرتبة الثالثة الفقرة السـابعة عشر-ة 
و التي نصـت علن "إجراء المهارات الرياضسية يعتمد علن اسـتيعاب المفاهيم الرياضـية "وبلغ متوســطها 2.67 ودر جة مو افقة عالية، وقد يعزئ ذلك إلى أن المفاهيم الرياضـية هي أسـاس المعرفة المفاهيمية ومكونات البنية الرياضـية ومنها المهارات الرياضـية فتعليم المفهوم الرياضي واكت سابه وا ستيعابه من قبل الطلبة حتما سي ساعد في ا ستيعاب وإتقان المهارات الريا ضية ، ويلاحظ من الجدول أعلاه أن أدنى الفقرات في المجال التي حصـلت على أقل ترتيب حسـب المتوسـط، وهي الفقرة الثالثة والتي نصــت على "تعتبر التجر بة ضرور ية لتعلم المفاهيم الرياضــية" وعلى متوسـط 2.12 ودرجة متوسـطة، وقد يعود هذا إلى تصــور المعلمين إلى أن المفاهيم الرياضية ليست جميعها تتطلب التجربة لتعليمها، فيمكن تعلمها من خلال الاكتشاف والاستقر اء والبرهان الرياضي، وحصلت علن المرتبة قبل الأخيرة الفقرة الخامسة عشرة والتي

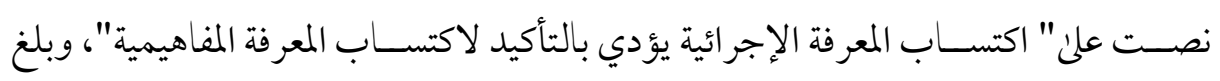
متوســطها 2.09 و بدر جةٍ متوســطةٍ، و هذا يدل على امتلاك المعلم التصــور حول المعر فة المفاهيمية والاجرائية و هذا شيء طبيعي أن المعر فة المفاهيمية تؤدي إلى اكتسـاب المعر فة الإجرائية وليس العكس، وحصلت علن المرتبة الأخيرة الفقرة الحادية عشر والتي ذصت علن "التعلم الإجرائي هو بمثا بة تطبيق للتعلم المفاهيمي". وبلغ متوسـطـها 2.03 و بدر جةٍ متوســطةٍ، وقد يعود هذا إلى تصــور المعلمين حول الاختلاف الجموهري بين التعلم الإجرائي والتعلم المفهومي الذي في الأول يسـتهدف الإجراءات والمهارات الر ياضــية وفي الآخر يستهدف تعلم المفاهيم الرياضية. النتائج المتعلقة بالإجابة على السؤال الثالث والذي نص: هل هناك فروق ذات دلالة إحصائية بين متوسطات استجابات عينة الدراسة تعزي إلى المتغيرات (المرحلة التعليمية، المؤهل العلمي،

$$
\text { سنوات الخبرة) }
$$


متغير المرحلة التعليمية: للإجابة عن السؤال الثالث بالجزء المتعلق بمتغير المرحلة التعليمية تم استخدام المتو سطات الحسابية والانحر افات المعيارية واختبار (تحليل التباين الأحادي) للتعرف علنى دلالة الفروق والجدول الآتي يوضح ذلك: جدول (8) اختبار تحليل التباين الأحادي لدلالة الفروق في متغير المرحلة التعليمية

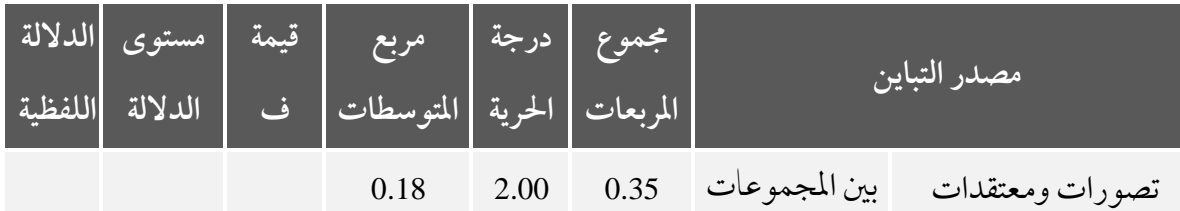

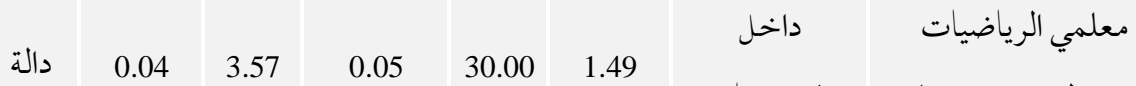
الإبستمولوجية حول طبيعة المجموعات

\begin{tabular}{|c|c|c|c|c|c|c|c|}
\hline & & & & 32.00 & 1.84 & المجموع & المفهوم الرياضي \\
\hline \multirow{3}{*}{ دالة } & \multirow{3}{*}{0.04} & \multirow{3}{*}{3.71} & 0.52 & 2.00 & 1.03 & بين المجموعات & \multirow{3}{*}{ تصورات ومعتقدات الإبستمولوجية حول تعلميلم } \\
\hline & & & 0.14 & 30.00 & 4.16 & المجموعات & \\
\hline & & & & 32.00 & 5.19 & المجموع & \\
\hline \multirow{3}{*}{ دالة } & \multirow{3}{*}{0.02} & \multirow{3}{*}{4.39} & 0.27 & 2.00 & 0.53 & بين المجموعات & \multirow{3}{*}{ الكلي } \\
\hline & & & 0.06 & 30.00 & 1.82 & المجموعات & \\
\hline & & & & 32.00 & 2.35 & المجموع & \\
\hline
\end{tabular}

ويتضـح من الجمدول السـابق أعلاه نتائج اختبار تحليل التباين الأحادي لدرجة وجهة نظر عينة الدرا سة حول للدرجة الكلية للا ستبيان وجميع ججالاتها تبعاً لمتغير المرحلة التعليمية، وبالنظر إلى الجلدول يتضـح أن قيمة (ف) دالة إحصـائيًا عند مسـتوى (0,05) للدرجة الكلية ولكل مجالات الاسـتبيان، أي أنه توجد فروق ذات دلالة احصـائية تعزئ لمتغير المرحلة هذا 
يدل أنه يوجد اختلاف في رؤية وجهة نظر عينة الدراسـة حول التصــورات الإبسـتمولوجية تعزئ لمتغير المرحلة التعليمية، وللتعرف علن اتجاه الفروق بين متغيرات المرحلة التعليمية، تم استخدام اختبار شيفيه للمقارنات البعدية ويتضح ذلك في الجدول الآتي: جدول (9) جدول شيفيه للمقارنات البعدية بمتغير المرحلة

\section{المتغيرات}

\section{المجالات}

المرحلة الابتدائية المتوسطة الثانوية

\begin{tabular}{|c|c|c|}
\hline \multirow[t]{2}{*}{$*$} & الابتدائية & \multirow{2}{*}{ الإبستمولوجية حول طبيعة المفهوم الرياضي ومعتقدات معلمي الرياضيات } \\
\hline & المتوسطة & \\
\hline & الثانوية & \\
\hline
\end{tabular}

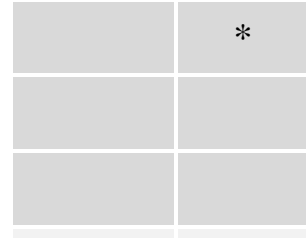

*

الإبستمولوجية حول تعلم المفهوم الرياضي

الابتدائية
المتوسطة الثانوية

الكلي

الفروق دالة إحصائياً عند مستوىن دلالة 0.05.

يتضح من الجمدول السابق أعلاه نتائج اختبار شيفيه للمقارنات البعدية لدلالة الفروق بين متوسـطات درجة وجهة نظر عينة البحث حول التصـورات الإبستمولوجية لمعلمي الرياضسيات حول المعرفة المفاهيمية حسـب متغير المرحلة التعليمية ويلاحظ من الجدول أنه هناك فروق بين معلمي الرياضيات في المرحلة الابتدائية والمرحلة المتوسطة لصالح معلمي المرحلة الابتدائية ، وهذا يعود إلى إن لدى معلم المرحلة الابتدائية الخلفية الكافية تلقوها أثناء دراسـتهم لأهمية تعلم وتعليم المفاهيم بالنسـبة للمرحلة التي يستهدفونها ، نظراً لإدر اك أهمية تأسـيس المفاهيم لدئ الطلاب في

\section{http://dx.doi.org/10.29009/ijres.3.2.9}


هذه الفئة العمرية وهذا يعود إلى طبيعة النمو المفاهيمي لدئ الطلاب في هذه الفئة العمرية، فكان هناك تو جه ملموس بالاهتحام بالمفاهيم من حيث الإعداد لمؤلاء المعلمين أو من حيث مـا تلقوه من تدريب أو غيره ، وهذا مـا يجعل المفاهيم الرياضـية تكون أكثر أهمية في بناء المعرفة الرياضــية في المرحلة الابتدائية عن المفاهيم الرياضـية في المرحلة المتوسـطة، وهذا ما قد يفسر-عدم وجود فروق ذات دلالة إحصــائية بين وجهة نظر معلمي المرحلة الابتدائية والثانوية من جهة وبين معلمي الرياضيات للمرحلة المتوسطة والثانوية من جهة أخرىن. متغير المؤهل: للإجابة عن السؤال الثالث بالجزء المتعلق بمتغير المؤهل تم استخدام متوسطات الرتب واختبار (مـان وتني) للتعرف على دلالة الفروق لمتغير المؤهل، والجمدول الآتي يوضح ذلك: جدول (10): اختبار مان ويتني للفرق بين متوسطي متغير المؤهل

\begin{tabular}{|c|c|c|c|c|c|c|c|}
\hline الدلالة & مستوى & قيمة & الرتب & متوسط & العدد & المؤهل & المحور \\
\hline \multirow{2}{*}{ غالة } & \multirow{2}{*}{0.86} & \multirow{2}{*}{$0.37-$} & 461.50 & 17.75 & 26 & بكالوريوس & تصورات ومعتقدات \\
\hline & & & 99.50 & 14.21 & 7 & ماجستير & طبيعة المفهوم \\
\hline \multirow{2}{*}{ غير } & \multirow{2}{*}{0.20} & \multirow{2}{*}{0.10} & 437.50 & 16.83 & 26 & بكالوريوس & تصعورات ومعتقدات \\
\hline & & & 123.50 & 17.64 & 7 & ماجستير & تعلم المفهوم الرياضي \\
\hline \multirow{2}{*}{ غير } & \multirow{2}{*}{0.11} & \multirow{2}{*}{$0.25-$} & 439.50 & 16.90 & 26 & بكالوريوس & \multirow{2}{*}{ الكلي } \\
\hline & & & 121.50 & 17.36 & 7 & ماجستير & \\
\hline
\end{tabular}


يتضح من الجمدول السابق أعلاه نتيجة اختبار (مان وتني)، للتعرف على دلالة الفروق في متغير المؤهل ويلاحظ من الجلدول أن قيمة (z) غير دالة إحصــائيًا عند مســتوئ دلالة (0.05) في الدرجة الكلية وكل محاور الاستبيان بين وجهة نظر العينة تعزى للمؤهل الدراسي، وهذا يدل أن درجة امتلاك التصورات الإبستمولوجية لمعلمي الرياضيات لا تختلف باختلاف المؤ هل العلمي، و قد يعزىن ذلك إلى أن غالبية مؤهلات الملاجسـتير تكون في المناهج العامة وليس في تخصص الرياضيات فلا يكون هناك عمق يذكر فيما يختص بالمفاهيم الريا ضية يكون فيه تميز عن ما يتلقاها المعلم في درجة البكالوريوس. متغير سنوات الخبرة: للإجابة عن السؤال الثالث بالجزء المتعلق بمتغير سنوات الخبرة تم استخدام متوسطات الرتب واختبار (كروسكال واليس) للتعرف على دلالة الفروق لمتغير

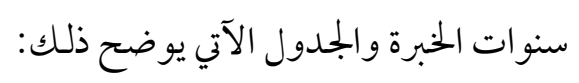

جدول (11) اختبار كروسكال واليس لدلالة الفروق بين متوسطات رتب متغير سنوات الخببرة

\begin{tabular}{|c|c|c|c|c|c|c|}
\hline اللفلالة & الدلالة & قربمة كا & متوسط & العدد & الخبرة & المجالات \\
\hline \multirow{3}{*}{ دالة } & \multirow{3}{*}{0.005} & \multirow{3}{*}{10.423} & 28.5 & 1 & سنو من 5 & \multirow{3}{*}{ تصعورات ومعتقدات } \\
\hline & & & 9.1 & 10 & من 5 المن اقل من & \\
\hline & & & 20.07 & 22 & 10 اكثر من ات & \\
\hline
\end{tabular}


Dr. Mohammad Hamad Muaitq alkhuzaim

Volume (3) No. (2) 2020

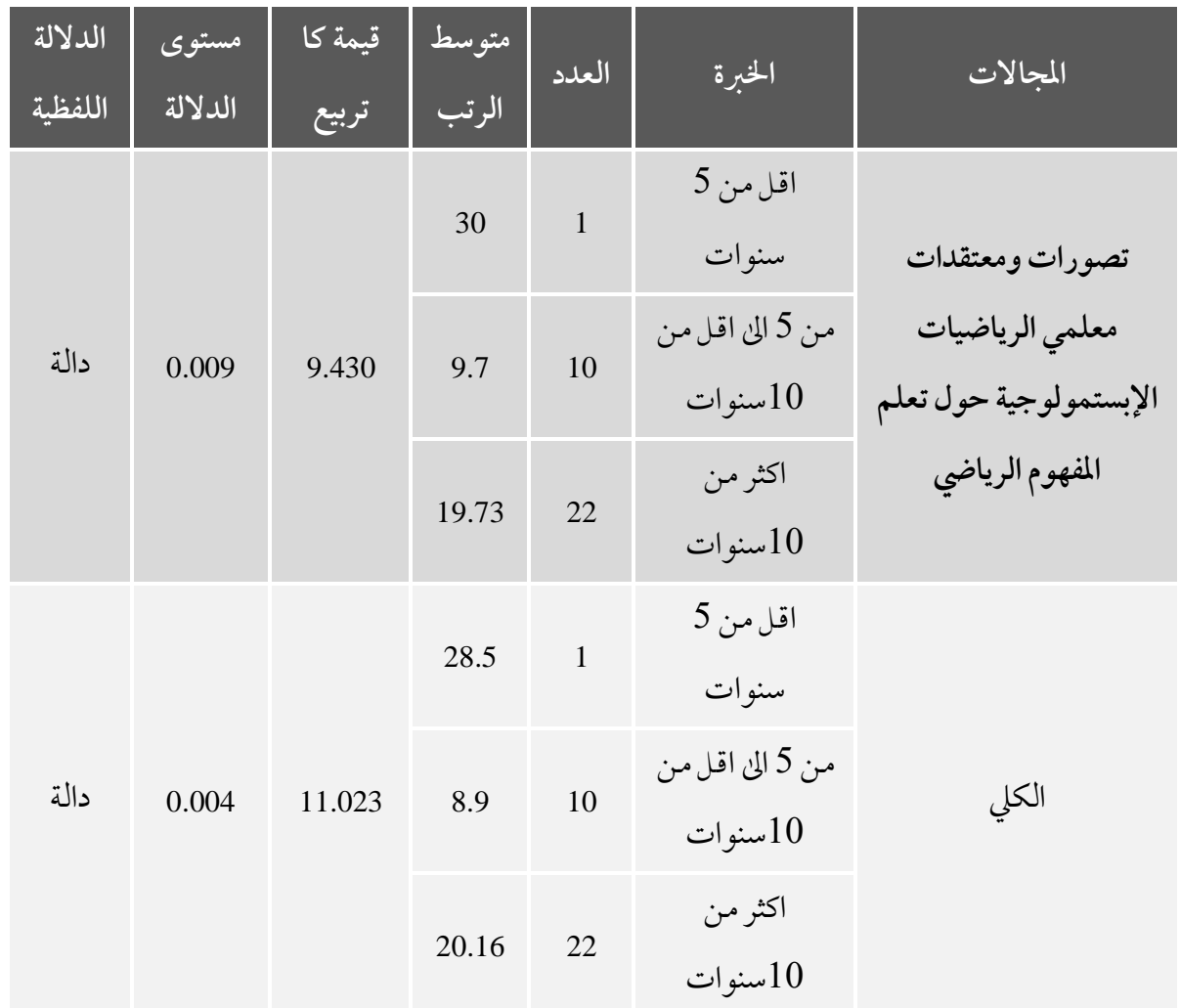

ويتضحسح من الجدول السـابق أعلاه نتائج اختبار كروسـكال واليس لدرجة وجهة نظر

عينة الدراسـة حول تصــورات ومعتقدات معلمي الرياضـيات الإبسـتمولوجية للمعرفة

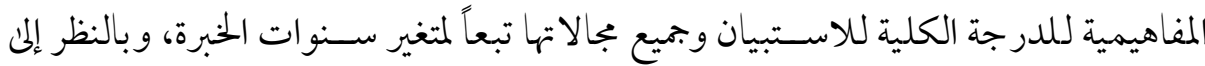
الجدول يتضـح أن قيمة (كا تربيع) دالة احصـائيًا عند مسـتوئ (0,05) للدرجة الكلية ولكل مجلات الاسـتبيان، و هذا يدل أنه يو جد اختلاف في رؤية وجهة نظر عينة الدراسـة حول

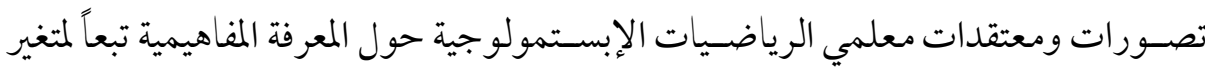

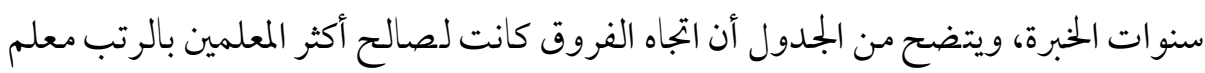
واحد سنوات خبرته أقل من 5 سنوات وقد يعزئ ذلك إلى حداثة خبرته ودرايثه حول المفاهيم

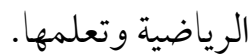

\section{http://dx.doi.org/10.29009/ijres.3.2.9}




\section{توصيات الدراسة:}

في ضوء نتائج الدراسة الحالية يقدم الباحث التوصيات الآتية:

تركيز الدورات التدريبية لمعلمي الرياضيات في مراحل التعليم العام على تعزيز تصوراتهم ومعتقداتهم الإبستمولوجية حول طبيعة المعرفة المفاهيمية.

إضافة برامج ودورات تدريبية لمعلمي الرياضيات لتنمية مهار اتهم التدريسية في ضوء تصوراتهم ومعتقداتهم الإبستمولو جية للمعرفة المفاهيمية وأساليب تعلمهاو تعليمها. تعريف معلمي الرياضيات بمفهوم علم الإبستمولوجية وكيفية فهم أصول المعرفة الرياضية. ضرورة التقويم المستمر لدرجة امتلاك معلمي الرياضيات التصورات الإبستمولوجية حول طبيعة وعملية تعلم وتعليم المفاهيم الرياضية. • لفت نظر مطوري مناهج الرياضيات لتضمين أصول المعرفة الرياضية(الإبستمولوجية) في كتب الرياضيات ودليل معلم الرياضيات لتنمية تصورات ومعتقدات معلمي الرياضيات والطلاب الإبستمولوجية حول المعرفة المفاهيمية. نشر ثقافة الإبستمولوجية كأحد العلوم الذي يبحث في أصول المعرفة من خلال الندوات الثقافية بما يعزز تصورات ومعتقدات معلمي الرياضيات الإبستمولوجية حول المعرفة الرياضية. 
في ضوء نتائج الدراسة الحالية يقترح الباحث إجراء الدراسات المستقبلية الآتية:

تصورات ومعتقدات معلمات الرياضيات في جميع مراحل التعليم العام حول المعرفة

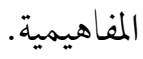

تصورات ومعتقدات معلمي الرياضيات الإبستمولوجية حول المعرفة المفاهيمية وعلاقتها بأنحاطهم التعليمية لها.

إجراء دراسة مشابهة لنفس الدراسة الحالية علن مناطق مختلفة غير التي في الدراسة الحالية.

تصورات ومعتقدات معلمي الرياضيات الإبستمولوجية حول المعرفة المفاهيمية وعلاقتها بتصوراتهم الإبستمولوجية حول المعرفة الإجرائية.

تصورات ومعتقدات معلمي الرياضيات الإبستمولوجية حول المعرفة المفاهيمية وعلاقتها بتصورات طلابهم هلا.

فاعلية برنامج تدريبي مقترح لتنمية التصورات الإبستمولوجية للمفاهيم الرياضية لدئ معلمي ومعلمات الرياضيات. 
1. أبو أسعد صلاح عبد اللطيف (2010) أساليب تدريس الرياضيات، عمان، دار الشروق.

2. أبو جحجوح، يجيئ (2013) طبيعة علم الفيزياء وعلاقته بطر ائق التدريس لدن معلمي

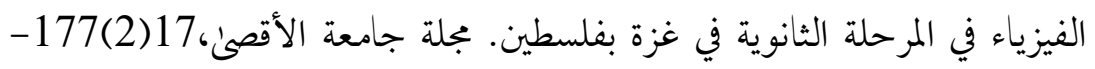

.217

3. أبو زينة، فريد (1997) الرياضيات مناهجها أصول تدريسها، ط3، عَّاّن، دار الفرقان.

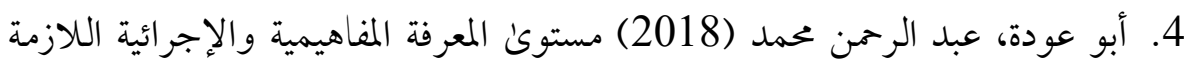
لتدريس الرياضيات في المرحلة الأساسية لدىن الطلبة المعلمين في الجامعة الإسلامية غزة، رسالة ماجستير، كلية التربية، الجامعة الإسلامية بغزة. 5. بدارنة أشرف محمود (2008): "المعتقدات الإبستمولوجية لدئ طلبة المدارس الثانوية الثرهية من العرب واليهود دراسة مقارنة"، رسالة ماجستير جامعة اليرموك الأردن. 6. البرصان، اسماعيل سالمه؛ رسمي، إيمان (2017): "المعرفة الإبستمولوجية لدئ معلمي الرياضيات للصف الثامن الأساسي في الأردن"، بجلة جامعة الخليل للبحوث، المجلد

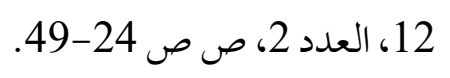

7. الحليسي، سعيد شبيب؛ السلولي، مسفر سعود (2016) واقع المارسات التدريسية للمعرفة المفاهيمية والاجرائية لدىن معلمي رياضيات المرحلة المتوسطة، المجلة الدولية التربوية المتخصصة، المجلد 5، العدد 7، ص ص 354 - 372. 8. روبير بلانشيه (1986): نظرية المعرفة العلمية الإبستمولوجية، ترجمة حسن عبد الحميد،

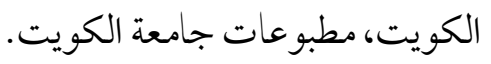


9. الزعبي، طلال؛ الشرع، إبراهيم؛ السلامات، محمد (2012): "معتقدات الطالبات

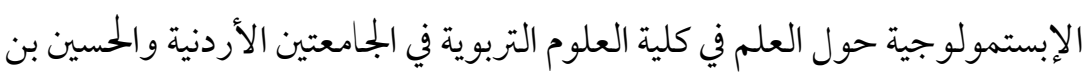

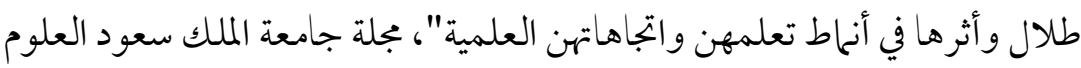

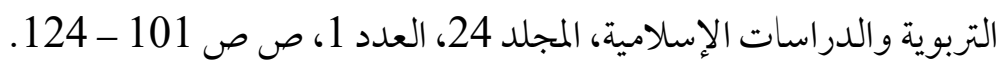
10. الزهراني، محمد سالر (2014): "مستوىن المعرفة المفاهيمية والإجرائية لطلاب الرياضيات بالمرحلة الابتدائية، رسالة ماجستير، جامعة أم القرىن. 11. سعيد وائل معين (2001): "تطور المعتقدات الإبستمولوجية لدئ طلبة البكالوريوس في كليات التربية الجامعات الأردنية رسالة ماجستير جامعة اليرموك لهون

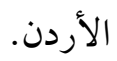

12. السلولي، مسفر بن سعود؛ خشان، أيمن حلمي؛ إبراهيم، إبراهيم بن رفعت (2010): "العلاقة بين استيعاب طلاب المرحلة الابتدائية بالمملكة العربية السعودية للمفاهيم المرتبطة بالعمليات الحسابية ومعتقدات معلميهم لهذا الاستيعاب" بجلة جامعة طيبة للعلوم التربوية المجلد 5 العدد 2 ص ص صمبئه بـ101-130. 13. سليم، مريم (1985) : علم تكوين المعرفة الإبستمولوجية عند بياجيه، بيروت، معهد الإنماء العمري الدراسات الإنسانية. 14. الشارقي، أحمد (1997) : المدخل لتدريس الرياضيات، ليبيا، الجامعة المفتوحة.

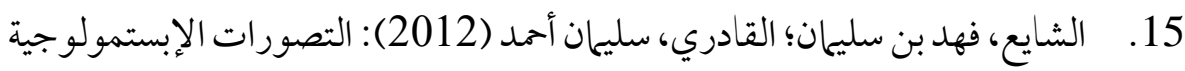

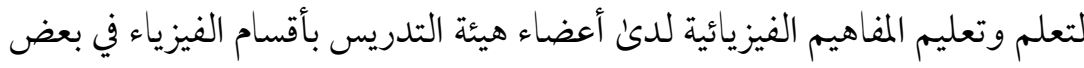
الجامعات السعودية والأردنية"، مجلة جامعة الملك سعود - العلوم التربوية والدراسات الإسلامية، المجلد 24 العدد 1، ص ص: صديه ، 310 - 285. 
16. الشريف، صالح إبراهيم (2016): "أثر استخدام استراتيجيات ما وراء المعرفة في المعرفة المفاهيمية لدئ الدارسين لتعليم الكبار بالمرحلة المتوسطة في المملكة العربية السعودية، الجمعية المصرية للقراءة والمعرفة، العدد 197، 127 - 174. 17. شعبان حسين (1993) : الفلسفة والعلم، دراسة نقدية، بيروت، دار التنوير. 18. الطراونة، عوض فائق، خصاونة، أمل عبد الله (2018): "معتقدات معلمي الرياضيات وعلاقتها بممارساتهم التدريسية"، بجلة دراسات- العلوم التربوية، المجلد

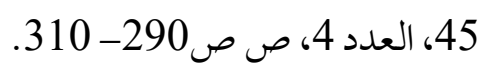

19. عابد، عدنان سليم (2002): "معتقدات الطلبة معلمي الرياضيات نحو حل المسألة ومدىئ تأثرها بتحصيلهم ومعتقداتهم بفاعليتهم التدريسية"، المجلة التربوية، جامعة

$$
\text { الكويت، المجلد 17، العدد 65، ص } 43 \text { - } 72 .
$$

20. عبيد، وليم (2000): تربويات الرياضيات، القاهرة، مكتبة الأنجلو المصرية. 21. عفيفي، محرم يميي محمد (2015): "فاعلية مناهج العلوم في تنمية مهارات الجلدل العلمي وفهم المحكات الإبستمولوجية له لدىن تلاميذ المرحلة المتوسطة بالمملكة العربية السعودية"، بجلة كلية التربية، العدد 39 المجلد2، ص ص: 230 - 181. 22. فرج الله، عبد الكريم موسى ( 2013): أساليب تدريس الرياضيات، عَّان، دار اليازوري.

23. القادري، سليمان أحمد (2012): "التصورات الإبستمولوجية لتعلم المفاهيم الفيزيائية لدى أعضاء هيئة التدريس وطلبة قسم الفيزياء بجامعة آل البيت في الأردن"، المجلة الدولية للأبحاث التربوية / جامعة الإمارات العربية المتحدة، العدد

$$
\text { 31 } 31
$$


24. القادري، سليمان أحمد؛ مومني، إبراهيم؛ قبلان، محمد أحمد (2010): "التصورات الإبستمولوجية لتعلم المفاهيم العلمية لدى معلمات الصفوف الثالثة الأولية وعلاقتها بمستوى خبرتهن التدريسية"، مجلة العلوم الإنسانية، العدد 33، ص ص 71 - 99. 25. القادري، سليمان أحمد؛ المومني، إبراهيم عبد الله (2010): "التصورات الإبستمولوجية لتعلم المفاهيم العلمية لدئ معلمات الصفوف الثلاثة الأولى وعلاقتها بمستوى خبرتهن التدريسية، بجلة العلوم الإنسانية، جامعة منتورى قسنطينة، العدد

$$
\text { 33، ص ص: } 99
$$

26. قاسم محمد (2008) المدخل إلى فلسفة العلوم. مصر .دار المعرفة الجامعية. المطرب، خالد بن سعد (2015): "المعرفة الرياضية الإجرائية والمفاهيمية اللازمة لمعلمي الصف بالمر حلة الابتدائية" بجلة رسالة التربية وعلم النفس جامعة الملك سعود

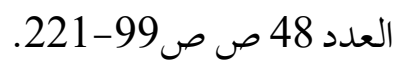

28. هاني، مرفت حامد محمد (2015): "فاعلية إستر اتيجية (PDEODE) القائمة على مبادئ النظرية البنائية في تنمية التحصيل في مادة الأحياء ومهارات ما وراء المعرفة والمعتقدات الإبستمولوجية لدىن طلاب الصف الأول الثانوي"، المجلة المصرية للتربية العلمية، المجلد 18 العدد 1، ص ص: 218 - 151. 29. الهويدي زيد (2006): أساليب وإستراتيجيات تدريس الرياضيات، العين، دار الكتاب الجامعي. 30. يمينة، تيرس (2017): "دراسة العلاقات بين المعتقدات الإبستمولوجية المعرفية ومهارات ما وراء المعرفة والاستراتيجيات الدافعة للتعلّم لدئ عَّنة من طلاب الجامعة"، رسالة ماجستير، العلوم الاجتماعية، جامعة وهر ان، الجزائر. 


\section{References:}

- $\quad$ Aspinwell, L., \& Miller, D. (1997):"'Students positive reliance on writing as a process to learn first semester calculus", Journal of institutional psychology, 24, pp.253-262.

- $\quad$ Cheng-Yaa, L., Jerry, B., Der-Ching, Y. \&Tsai-Wei (2013): Preservice Teachers Conceptual and Procedural Knowledge of Fraction Operation: A comparative Study of the United State and Taiwan. School science and mathematics, 113(1), pp. 41-51.

- Khishfe, R. (2013).Relationship between Nature of Science Understandings and Argumentation Skills:A Role for Counterargument and Contextual Factors, Journal of Research in Science Teaching, V(49),N(4),pp.489-514.

- $\quad$ Longstreet, W. (1990). The social studies: In search of an epistemology. Social Studies, 81(6), pp.244-249.

- National Council of Teacher of Mathematics NCTM.(2000). Principles and Standards for School Mathematics. Reston, VA: Author. 


$$
\begin{aligned}
& \text { 口 } \\
& \text { 口 متوسط } \\
& \text { 口 ابتدائي } \\
& \text { المر حلة التدريسية } \\
& \text { أكثر من } 10 \\
& \text { من } 5 \text { الى } 10 \\
& \text { 口ا }
\end{aligned}
$$

تصورات ومعتقدات معلمي الرياضيات الابستمولوجية المتعلقة بطبيعة المفهوم الرياضي.

مو افقى
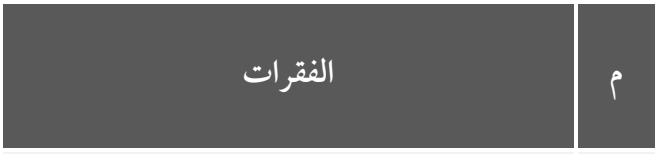

تعد المفاهيم الرياضية اللبنات الأساسية لكل

$$
\text { مكونات المعرفة الرياضية }
$$

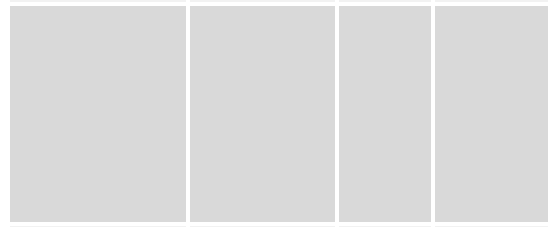

أصل المفاهيم الرياضية هو العقل وليس العاله

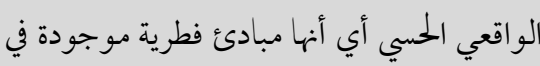

.2

العقل

المفهوم الرياضي مصرها التجربة فبالتالي مكتسب المعرب

من التجربة

\section{1}



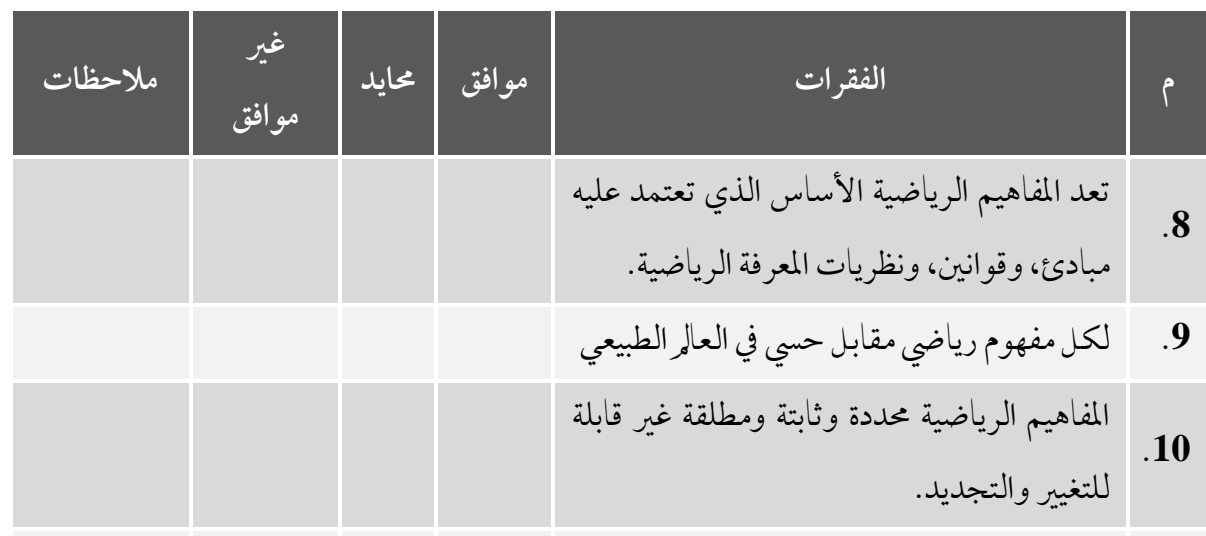

تعد المفاهيم الرياضية الأساس الذي تعتمد عليه مبادئ، وقو انين، ونظريات المعرفة الرياضية.

لكل مفهوم رياضي مقابل حسي في العالر الطبيعي

المفاهيم الرياضية محددة وثابتة ومطلقة غير قابلة للتغيير والتجديد.

المفاهيم لا توجد في العاله الحسي لأنه نسبي ومتغير

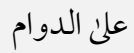

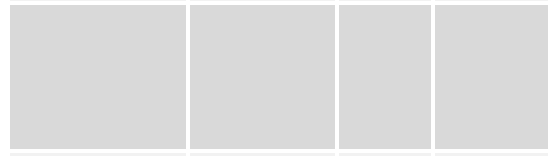

قد تكون التجربة الحسية مصدر للمفاهيم الرياضية

المفهوم الرياضي ليس شيئًا مسوساً قائماً في الو اقع المفاهيم الرياضية يمكن التحقق من صحتها

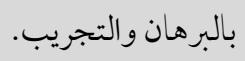

معظم المفاهيم الرياضية مجردة.

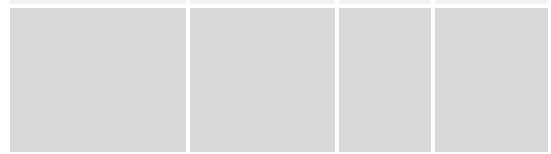

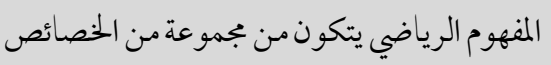

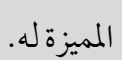

لا يمكن أن يقوم فكرٌ رياضي بدون مفاهيم 


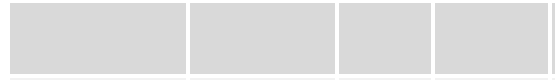

المصطلحات الرياضية هي مفاهيم رياضية ثابتة.

تختلف المفاهيم الرياضية عن الرموز الرياضية عن

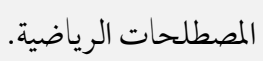

يمكن التعبير عن المفهوم الرياضي بالمصطلح

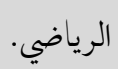

يمكن تمثيل المفهوم الرياضي من خلال الشكل

ترتبط المفاهيم الرياضية في مختلف فروع ومو اضيع الرياضيات مع بعضها البعض.

العلاقة تكاملية بين المفاهيم في مقرر الرياضيات

31. والمفاهيم في المقررات الدراسية الأخرى ذات

العلاقة.

للمفاهيم الرياضية أنواع مثل: البسيطة والمركبة. الأولية والثانوية والمحسو سة والمجردة. 


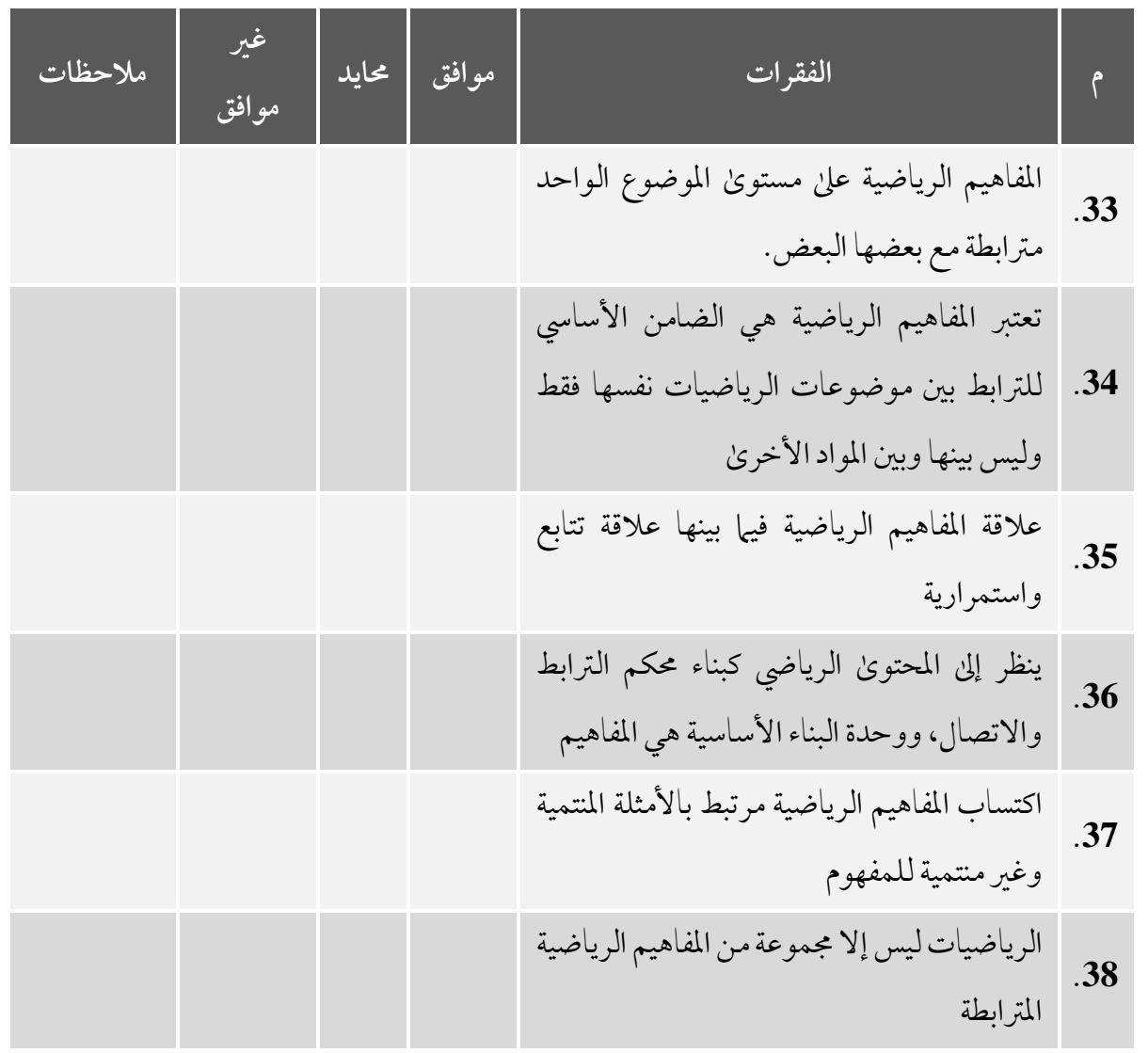


تصورات ومعتقدات معلمي الرياضيات الابستمولوجية حول تعلم المفهوم الرياضي. موافق

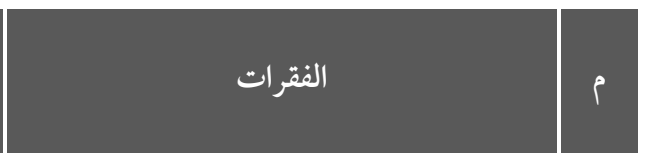

اكتساب بعض المفاهيم الرياضية يسهل اكتساب

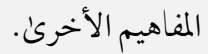

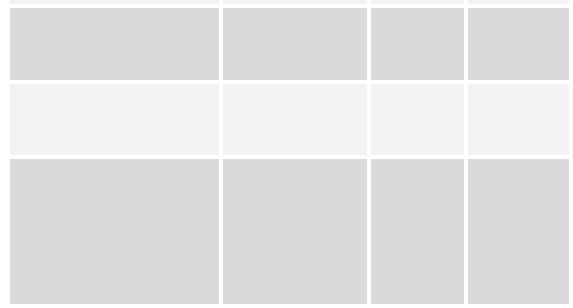

2 2

3

قابلية تعلم المفاهيم يمكن أن تتأثر بالبيئة المحيطة.

.4

ترتبط بعض المفاهيم الرياضية لتشكل مفهوم

$$
\text { رياضي واحد. }
$$

.5

تعلم المفاهيم الرياضية تدخل في حل مشكلات

$$
\begin{aligned}
& \text { تو اجهنا في حياتنا } \\
& \text { اليومية }
\end{aligned}
$$

.6

جميع المفاهيم الرياضية قابلة للتعلم لكن بدرجات متفاوتة

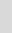




\begin{tabular}{|c|c|c|c|c|c|}
\hline ملاحظات & 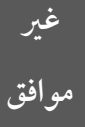 & محايد & موافق & الفقرات & $p$ \\
\hline & & & & المفاهيمي الإجرائي هو بمثابة تطبيق للتعلم & .11 \\
\hline & & & & 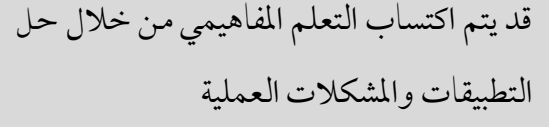 & .12 \\
\hline & & & & 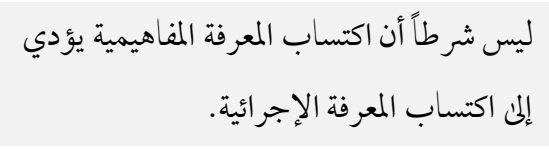 & .13 \\
\hline & & & & 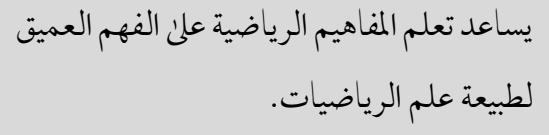 & .14 \\
\hline & & & & 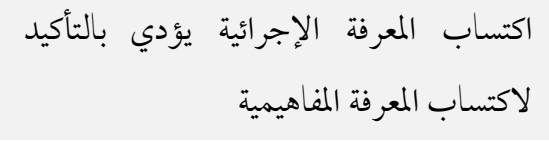 & .15 \\
\hline & & & & 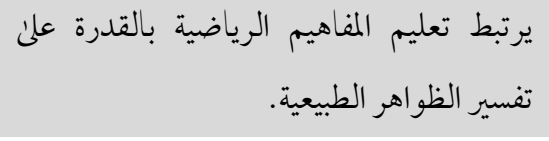 & .16 \\
\hline & & & & 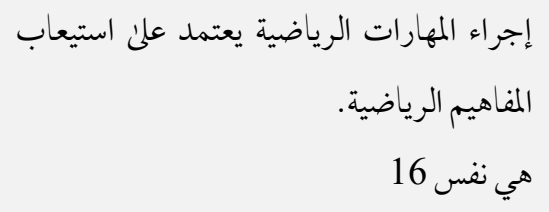 & .17 \\
\hline & & & & بتعاف التمافميات الرياضية يرتبط مباشرة & .18 \\
\hline
\end{tabular}

